\title{
Strong constraints on aerosol-cloud interactions from volcanic eruptions
}

Article

Accepted Version

Malavelle, F. F., Haywood, J. M., Jones, A., Gettelman, A., Clarisse, L., Bauduin, S., Allan, R. P., Karset, I. H. H., Kristjánsson, J. E., Oreopoulos, L., Cho, N., Lee, D., Bellouin, N., Boucher, O., Grosvenor, D. P., Carslaw, K. S., Dhomse, S., Mann, G. W., Schmidt, A., Coe, H., Hartley, M. E., Dalvi, M., Hill, A. A., Johnson, B. T., Johnson, C. E., Knight, J. R., O'Connor, F. M., Partridge, D. G., Stier, P., Myhre, G., Platnick, S., Stephens, G. L., Takahashi, H. and Thordarson, T. (2017) Strong constraints on aerosol-cloud interactions from volcanic eruptions. Nature, 546 (7659). pp. 485-491. ISSN 0028-0836 doi: https://doi.org/10.1038/nature22974 Available at https://centaur.reading.ac.uk/70926/

It is advisable to refer to the publisher's version if you intend to cite from the work. See Guidance on citing.

Published version at: http://dx.doi.org/10.1038/nature22974

To link to this article DOI: http://dx.doi.org/10.1038/nature22974

Publisher: Nature Publishing Group

All outputs in CentAUR are protected by Intellectual Property Rights law, including copyright law. Copyright and IPR is retained by the creators or other copyright holders. Terms and conditions for use of this material are defined in 
the End User Agreement.

www.reading.ac.uk/centaur

\section{CentAUR}

Central Archive at the University of Reading

Reading's research outputs online 
Authors: Florent F. Malavelle ${ }^{1 *}$, Jim M. Haywood ${ }^{1,2}$, Andy Jones ${ }^{2}$, Andrew Gettelman³, Lieven Clarisse ${ }^{4}$, Sophie Bauduin ${ }^{4}$, Richard P. Allan ${ }^{5,6}$, Inger Helene H. Karset ${ }^{7}$, Jón Egill Kristjánsson ${ }^{7, \$}$, Lazaros Oreopoulos ${ }^{8}$, Nayeong $\mathrm{Cho}^{8,9}$, Dongmin $\mathrm{Lee}^{8,10}$, Nicolas Bellouin $^{5}$, Olivier Boucher ${ }^{11}$, Daniel P. Grosvenor ${ }^{12}$, Ken S. Carslaw ${ }^{12}$, Sandip Dhomse $^{12}$, Graham W. Mann ${ }^{12,13}$, Anja Schmidt ${ }^{12}$, Hugh Coe ${ }^{14}$, Margaret E. Hartley ${ }^{14}$, Thordarson $^{21}$.

Affiliations:

${ }^{1}$ College of Engineering, Mathematics, and Physical Sciences, University of Exeter, Exeter, UK.

${ }^{2}$ Met Office Hadley Centre, Exeter, UK.

${ }^{3}$ National Center for Atmospheric Research, Boulder, Colorado, USA.

${ }^{4}$ Chimie Quantique et Photophysique CP160/09, Université Libre de Bruxelles (ULB),

Bruxelles, Belgium.

${ }^{5}$ Department of Meteorology, University of Reading, Reading, UK.

${ }^{6}$ National Centre for Earth Observation, University of Reading, UK.

${ }^{7}$ Department of Geosciences, University of Oslo, Oslo, Norway.

${ }^{8}$ Earth Sciences Division, NASA GSFC, Greenbelt, Maryland, USA.

${ }^{9}$ USRA, Columbia, Maryland, USA.

${ }^{10}$ Morgan State University, Baltimore, Maryland, USA. 
${ }^{12}$ School of Earth and Environment, University of Leeds, Leeds, UK.

${ }^{13}$ National Centre for Atmospheric Science, University of Leeds, Leeds, UK.

${ }^{14}$ School of Earth and Environmental Sciences, University of Manchester, Manchester, UK.

${ }^{15}$ Department of Environmental Science and Analytical Chemistry, University of Stockholm,

31 Stockholm, Sweden

${ }^{16}$ Bert Bolin Centre for Climate Research, University of Stockholm, Stockholm, Sweden

${ }^{17}$ Atmospheric, Oceanic and Planetary Physics, Department of Physics, University of Oxford, 34 Oxford, UK.

${ }^{18}$ Center for International Climate and Environmental Research, Oslo, Norway.

${ }^{19}$ Jet Propulsion Laboratory, California Institute of Technology, Pasadena, California, USA.

${ }^{20}$ Joint Institute for Regional Earth System Science and Engineering, University of California,

Los Angeles, California, USA

${ }^{21}$ Faculty of Earth Sciences, University of Iceland, Reykjavik, Iceland.

*Corresponding author: f.malavelle@exeter.ac.uk

${ }^{\$}$ Deceased $14^{\text {th }}$ August 2016.

\#Now at College of Engineering, Mathematics, and Physical Sciences, University of Exeter, Exeter, UK.

\section{Summary (149 words of referenced text):}

The climate impact of aerosols is highly uncertain owing primarily to their poorly quantified influence on cloud properties. During 2014-15, a fissure eruption in Holuhraun (Iceland) emitted huge quantities of sulphur dioxide, resulting in significant reductions in liquid cloud droplet size. Using satellite observations and detailed modelling, we estimate a global mean radiative forcing from the resulting aerosol-induced cloud brightening for the time of the eruption of around $-0.2 \mathrm{~W} \cdot \mathrm{m}^{-2}$. Changes in cloud amount or liquid water path are undetectable, indicating that these aerosol-cloud indirect effects are modest. It supports the 
idea that cloud systems are well buffered against aerosol changes as only impacts on cloud effective radius appear relevant from a climate perspective, thus providing a strong constraint on aerosol-cloud interactions. This result will reduce uncertainties in future climate projections as we are able to reject the results from climate models with an excessive liquid water path response.

Main Text: (3103 words of referenced text, including concluding paragraph)

\section{The 2014-15 eruption at Holuhraun (486 words of referenced text):}

Anthropogenic emissions that affect climate are not just confined to greenhouse gases.

Sulphur dioxide and other pollutants form atmospheric aerosols that can scatter and absorb sunlight and can influence the properties of clouds, modulating the Earth-atmosphere energy balance. Aerosols act as cloud condensation nuclei $(\mathrm{CCN})$; an increase in $\mathrm{CCN}$ translates into a higher number of smaller, more reflective cloud droplets that scatter more sunlight back to space $^{1}$ (the 'first' indirect effect of aerosols). Smaller cloud droplets decrease the efficiency of collision-coalescence processes that are pivotal in rain initiation, thus aerosol-influenced clouds may retain more liquid water and extend coverage/lifetime ${ }^{2,3}$ (the 'second' or 'cloud lifetime' indirect effect). Aerosols usually co-vary with key environmental variables making it difficult to disentangle aerosol-cloud impacts from meteorological variability ${ }^{4-6}$. Additionally, clouds themselves are complex transient systems subject to dynamical feedbacks (e.g. cloud top entrainment/evaporation, invigoration of convection) which influence cloud response ${ }^{7-12}$. These aspects present great challenges in evaluating and constraining aerosol-cloud interactions (ACI) in General Circulation Models (GCM) $)^{13-17}$, with particular contentious debate surrounding the relative importance of these feedback mechanisms.

Nonetheless, anthropogenic aerosol emissions are thought to cool the Earth via indirect effects $^{17}$, but the uncertainty ranges from -1.2 to $-0.0 \mathrm{~W} \cdot \mathrm{m}^{-2}$ (90\% confidence interval) due to i) a lack of characterization of the pre-industrial aerosol state ${ }^{15,18,19}$, and ii) model parametric 
81 and structural errors in representing cloud responses to aerosol changes ${ }^{16,18,20,21}$. It is estimated that uncertainty in the pre-industrial state can account for approximately $30 \%$ of total ACI uncertainty ${ }^{18,21}$ while representation of chemistry-aerosol-cloud processes in models is responsible for the remaining $70 \%$ uncertainty $^{16,21}$. Recently, a framework to break down uncertainties in the causal chain from emission to radiative forcing showed that the sources of uncertainty within different GCMs differ greatly ${ }^{16}$.

Volcanic eruptions provide invaluable natural experiments to investigate the role of largescale aerosol injection in the Earth system ${ }^{22-26}$. There have been several Icelandic volcanic eruptions over recent years; Eyjafjallajökull erupted in 2010, Grímsvötn in 2011 and Holuhraun in 2014-15. At its peak, the 2014-15 eruption at Holuhraun emitted $\sim 120 \mathrm{kt}$ of sulphur dioxide $\left(\mathrm{SO}_{2}\right)$ per day into the atmosphere, a rate some four times higher than all 28 European Union member states or over a third of global emission rates. Iceland became in effect a continental-scale pollution source of $\mathrm{SO}_{2} ; \mathrm{SO}_{2}$ is readily oxidised via gas- and aqueous-phase reactions, producing a massive aerosol plume in a near-pristine environment where clouds should be most susceptible to aerosol concentrations ${ }^{16,18,27}$.

We advance upon preliminary observational assessments of the impact of the 2014-15 eruption at Holuhraun ${ }^{28,29}$ through an extensive observational analysis that includes a statistical evaluation of the significance of the observed spatial distribution of the cloud perturbations to untangle the impacts of aerosol/meteorological impacts. We then assess the simulation from a range of different climate models and assess the performance against available observations. Finally, we show that observations of a volcanic plume (Mt. Kilauea, Hawaii) in an entirely different meteorological regime exhibit similar overall impacts.

\section{Impact of the eruption on clouds $(2140-20=2120$ words of referenced text $)$ :}

Following the lifecycle of sulphur from emission, our initial analysis concentrates on the coherence of $\mathrm{SO}_{2}$ detected by the Infrared Atmospheric Sounding Interferometer (IASI) sensor (Supplementary M1) and the HadGEM3 GCM that is constrained by observed 
temperatures and winds (i.e. nudged, Supplementary M2). IASI retrievals use the discrete spectral absorption structure of $\mathrm{SO}_{2}$ to determine concentrations ${ }^{30}$. Comparisons of IASI $\mathrm{SO}_{2}$ observations from explosive volcanic eruptions against model simulations have proven

111 valuable in the past ${ }^{31,32}$. The processing procedure for quantitative comparison between IASI

112 and HadGEM3 data uses only data that are spatially and temporally coherent (Supplementary

113 M3).

114 There is considerable uncertainty in the quantitative emission of $\mathrm{SO}_{2}$ from the 2014-15

115 eruption at Holuhraun. A previous study ${ }^{28}$ assumed a constant emission rate of 40 $116 \mathrm{kt}\left[\mathrm{SO}_{2}\right] /$ day based on initial estimates of degassing. As our standard scenario (STAN) we use

117 an empirical relationship between degassed sulphur and $\mathrm{TiO}_{2} / \mathrm{FeO}$ ratios and lava production

118 derived from Icelandic basaltic flood lava eruptions ${ }^{33}$ which suggests significantly higher 119 emissions during the early phase of the eruption in September, but we also investigate a 120 simulation where a constant $40 \mathrm{ktSO}_{2} /$ day is released (40KT scenario). The model 121 simulations and IASI retrievals of column $\mathrm{SO}_{2}$ are shown in Figure 1 (40KT emission 122 scenario shown in Supplementary S1).

$* * *$ Insert Figure 1 here $* * *$

126 The distribution and the magnitude of the column loading of $\mathrm{SO}_{2}$ detected by IASI are similar 127 to those derived from HadGEM3, showing that the GCM nudging scheme and the assumed 128 altitude of the emissions in the STAN scenario (surface to $3 \mathrm{~km}$ ) reproduces the week to week spatial variability and magnitude of observed column $\mathrm{SO}_{2}$ (SI-SO2_animation.mp4). While the spatial distribution of sulphate aerosol optical depth $(A O D)$ caused by the eruption can be determined easily in the model (Supplementary Fig. S2.1), detection of the aerosol

132 plume over the north Atlantic in the MODIS data is hampered by the mutual exclusivity of aerosol and cloud retrievals. The predominance of cloudy scenes makes accurate detection of the aerosol plume in monthly-mean MODIS data extremely challenging (Supplementary S2). 
135 Nonetheless, despite lacking observations of $A O D$, we can look for evidence of perturbations 136 caused by aerosols on cloud properties. We examine the perturbation to retrieved cloud top

137 droplet effective radius $\left(r_{\text {eff }}\right)$ in September and October 2014 using collection 051 monthly 138 mean data from MODIS AQUA (MYD08, Supplementary M4) over the period 2002-2014.

139 MODIS AQUA data are not subject to the degradation in performance of the sensors at 140 visible wavelengths that has recently been documented for the MODIS TERRA ${ }^{34}$ sensor

141 (Supplementary S3). We present a summary of the change in $r_{\text {eff, }}, \Delta r_{\text {eff, }}$, for October 2014 142 compared to the long term 2002-2013 mean in Figure 2a. A full analysis of the year-to-year 143 variability in $\Delta r_{\text {eff }}$ is presented in Supplementary S4.

***Insert Figure 2 here $* * *$

147 There is clear evidence of a signal in $\Delta r_{\text {eff }}$ in October (Figures 2a) and September 148 (Supplementary Fig. S5.1a). Pixels that are statistically significantly different from the 20021492013 climatological mean at 95\% confidence occur over the entire breadth of the north 150 Atlantic. The spatial distribution of $\Delta r_{\text {eff }}$ is governed by the prevailing wind conditions that advect the volcanic plume and are quantitatively similar to those noted in Collection 006 MODIS data ${ }^{29}$.

153 Figures 3 a show the corresponding $\Delta r_{\text {eff }}$ derived from the model in October (for September,

154 Supplementary Fig. S5.2a). The observations and modelling show obvious similarities in spatial distribution. In addition to the spatial coherence in $\Delta r_{e f f}$, the changes in the model of $-1.21 \mu \mathrm{m}$ (September) and $-0.68 \mu \mathrm{m}$ (October) are within $30 \%$ of MODIS $\Delta r_{\text {eff }}$ of $-0.98 \mu \mathrm{m}$ (September) and $-0.97 \mu \mathrm{m}$ (October) for the domain shown in Figure 2. 
161 There are similarities between the MODIS and HadGEM3 probability distribution functions 162 (Figures $2 \mathrm{~b}$ and $3 \mathrm{~b}$ ) with a shift to smaller $r_{\text {eff }}$ for the year of the eruption. Almost all high 163 values of $r_{\text {eff }}$ (i.e. $r_{\text {eff }}>\sim 16 \mu \mathrm{m}$ for MODIS and $r_{\text {eff }}>\sim 11 \mu \mathrm{m}$ for HadGEM3) are absent in 1642014 suggesting that clouds with high $r_{\text {eff }}$ are entirely absent from the domain in both the 165 observations and the model. There are obvious discrepancies in the absolute magnitude of $r_{\text {eff }}$ 166 between MODIS and HadGEM3. MODIS retrievals of $r_{\text {eff }}$ from the MYD06 product in liquid 167 water cloud regimes have been shown to be significantly larger than those derived from other satellite sensor products, mainly due to the algorithm's use of a different primary spectral

169 channel relative to other products ${ }^{35,36}$. Nevertheless, $\Delta r_{\text {eff }}$ is in encouraging agreement as this 170 quantity, along with changes in cloud liquid water path $(L W P)$, needs to be accurately represented if aerosol-cloud interactions are to be better quantified. As with $r_{\text {eff }}$, there are similarities between the MODIS and HadGEM3 for $\triangle L W P$ (Figure 2c-d and Figure 3c-d), however, evidence of a clear signal due to the volcano is neither observed or modelled.

174 Additionally, we also found that perturbations in the monthly mean cloud fraction from

175 MODIS are negligible, both in September and October as previously reported ${ }^{29}$.

It is incumbent on any study attributing $\Delta r_{\text {eff }}$ to volcanic emissions to prove the causality

177 beyond reasonable doubt, i.e. that the changes are not due to natural meteorological 178 variability. The meteorological analyses in Supplementary S6 suggest that, while in

179 September 2014 the southern part of the spatial domain shown in Figure 2 is somewhat influenced by anomalous easterlies bringing pollution from the European continent over the easternmost Atlantic Ocean and hence influencing $r_{\text {eff }}$, the perturbations to $r_{\text {eff }}$ during October 2014 are entirely of volcanic origin.

183 MODIS and HadGEM3 show a similar spatial distribution and magnitude for October for the perturbation in cloud droplet number concentration $\left(\Delta N_{d}\right)$, but a smaller $\Delta N_{d}$ in MODIS than in HadGEM3 for September 2014 (Supplementary S7.2). Once $r_{\text {eff }}$ is reduced, the autoconversion process whereby cloud droplets grow to sufficient size to form precipitation 
187 may be inhibited, leading to clouds with increased liquid water path ${ }^{3}$. The cloud optical 188 depth, $\tau_{\text {cloud }}$, is related to $r_{\text {eff }}$ and $L W P$ and the density of water $(\rho)$ by the approximation:

$$
\tau_{\text {cloud }} \cong \frac{3 \text { LWP }}{2 \rho \mathrm{r}_{\text {eff }}}
$$

190 We use HadGEM3 to assess the detectability of perturbations against natural variability. Two

191 different methods are pursued using the nudged model; firstly, assessing model simulations

192 with and without the emissions from the eruption for the year 2014 (HOL $\left.2014-\mathrm{NO}_{-} \mathrm{HOL}_{2014}\right)$, and secondly assessing model simulations including emissions from Holuhraun for 2014 against simulations for 2002-2013 (HOL $2014-\mathrm{NO}_{\text {HOL }}$ 2002-2013). While the former method allows the 'cleanest' assessment of the impacts of the eruption (as the meteorology is effectively identical and meteorological variability is removed), the second method allows assessment of the statistical significance against the natural meteorological variability. This provides an assessment that is directly comparable to observations and can be used to effectively isolate signal from noise ${ }^{37}$ (Supplementary S7).

\section{$* * *$ Insert Figure 4 here $* * *$}

Figure 4 shows that $\triangle A O D, \Delta N_{d}$, and $\Delta r_{\text {eff }}$ are statistically significant at $95 \%$ confidence across the majority of latitudes. The fact that the simulations from [HOL $\left.2014-\mathrm{NO}_{-} \mathrm{HOL}_{2014}\right]$ and [HOL $\left.2014-\mathrm{NO}_{-} \mathrm{HOL}_{2002-2013}\right]$ are similar for these variables again indicates that the impacts of natural meteorological variability on these variables is small (i.e. NO_HOL $2014 \approx$ NO_HOL 2002-2013). For $\Delta L W P$, no statistically significant changes are evident at either $95 \%$ or $67 \%$ confidence, suggesting that meteorological variability provides a far stronger control on cloud $L W P$ than aerosol (Supplementary S7.3). With $\triangle L W P$ being due to meteorological

210 noise, $\Delta \tau_{\text {cloud }}$ is driven by $\Delta r_{\text {eff }}$ and Figure 4e suggests that the perturbations to $\tau_{\text {cloud }}$ north of 211 around $67^{\circ} \mathrm{N} / 57^{\circ} \mathrm{N}$, which are significant at the $95 \% / 67 \%$ confidence level, are due to the

212 2014-15 Holuhraun eruption. Our simulations suggest that Top of Atmosphere changes in 
213 short wave radiation $\left(\triangle T o A_{S W}\right)$ are unlikely to be detectable at $95 \%$ or even $67 \%$ confidence

214 when compared to natural variability. More details supporting this assertion are given in

215 Supplementary S7.5 which uses satellite observations of the Earth's radiation budget.

216 We have shown that HadGEM3 is capable of representing observations of aerosol-cloud 217 interactions with a reasonable representation of the perturbation to $r_{\text {eff }}$ but minimal 218 perturbation to $L W P$. To demonstrate the practical value of the study, we repeat the

219 simulations with other models. First, we use HadGEM3 but using the older single moment 220 CLASSIC $^{38}$ aerosol scheme instead of the new two-moment UKCA/GLOMAP-mode 221 scheme ${ }^{39}$. We also perform calculations with the NCAR Community Atmosphere Model $^{28}$ 222 (CAM5-NCAR) and the atmospheric component of an intermediate version of the Norwegian Earth System Model $^{40}$ (CAM5-Oslo), driven using nominally the same emissions and plume top height. CAM5-NCAR has been used previously in free-running mode to provide an initial estimate of the radiative forcing of the 2014-15 Holuhraun eruption ${ }^{28}$, but as in the HadGEM3 simulations we run CAM5-NCAR and CAM5-Oslo in nudged mode to simulate the meteorology during the eruption as closely as possible. Figure 5 shows a comparison of $\Delta r_{\text {eff }}$ and $\triangle L W P$ derived from $\mathrm{HOL}_{2014}-\mathrm{NO}_{-} \mathrm{HOL}_{2014}$ simulations from HadGEM3, HadGEM3-CLASSIC, CAM5-NCAR, CAM5-Oslo and MODIS for October. We chose October as the contribution from continental Europe pollution to cloud property anomalies has been shown to be small (Supplementary S4-6-7; Supplementary S8 shows the impacts on cloud properties in September).

$* * *$ Insert Figure 5 here $* * *$

It is immediately apparent from the first column of Figure 5 that HadGEM3 using UKCA, CAM5-NCAR, and CAM5-Oslo are able to accurately model the impact on $\Delta r_{\text {eff }}$, while HadGEM3-CLASSIC produces an impact that is too strong when compared to the MODIS observations owing to the single moment nature of the aerosol scheme (Supplementary S9). 
For $\triangle L W P$, as we have seen from the multi-year analysis of MODIS (Supplementary Fig.

241 S7.3), the meteorological variability is the controlling factor. Even with meteorological

242 variability suppressed in these [HOL $\left.2014-\mathrm{NO}_{-} \mathrm{HOL}_{2014}\right]$ results, HadGEM3 using UKCA

243 shows only a very limited increase in LWP (Fig. 5f), HadGEM3-CLASSIC and CAM5-Oslo

244 show a progressively more significant response whereas CAM5-NCAR shows a much larger

245 response (Fig. 5h).

246 It is insightful to examine the influence of the eruption on precipitation in both observations

247 and models using a similar analysis (Supplementary S10). We observe that there is little

248 impact on precipitation indicating that the cloud system readjusts to a new equilibrium with

249 little impact on either $L W P$ or precipitation. The larger response in CAM5-NCAR $(\triangle L W P>$

25016 g.m ${ }^{-2}$ ) is not supported by the MODIS observations where the 2002-2013 domain mean

251 standard deviation in $\triangle L W P$ is $\sim 4.5 \mathrm{~g} . \mathrm{m}^{-2}$. Thus, we are able to use the eruption to evaluate

252 the models: HadGEM3 using UKCA and CAM5-Olso perform in a manner consistent with

253 the MODIS observations while HadGEM3-CLASSIC and CAM5-NCAR do not. Moreover,

254 the fact that changes in $L W P$ are not detectable above natural variability suggests that

255 aerosol-cloud interactions beyond the impact on $r_{\text {eff }}$ are small (i.e. net second indirect effects

256 are small).

257 The effective radiative forcing (ERF) from the event may be estimated from the difference

258 between the top of atmosphere net irradiances from simulations including and excluding the

259 volcanic emissions. The global ERF from HadGEM3 over the September-October 2014

260 period is estimated at $-0.21 \mathrm{~W} \cdot \mathrm{m}^{-2}$. Tests using an offline version of the radiation code reveal

261 that the presence of overlying ice-cloud weakens the ERF by approximately $20 \%$

262 (Supplementary S11).

263 We also investigate whether a fissure eruption of this magnitude could have a more 264 significant radiative impact if the timing/location of the eruptions were different 265 (Supplementary S12). Our simulations suggest that for contrasting scenarios the global ERF 266 would $i)$ strengthen to $-0.29 \mathrm{~W} \cdot \mathrm{m}^{-2}(+40 \%)$ if the eruption commenced at the beginning of 
267 June, ii) strengthen to $-0.49 \mathrm{~W} \cdot \mathrm{m}^{-2}(+140 \%)$ if the fissure eruption had occurred in an area of 268 South America where it could affect clouds in a stratocumulus-dominated regime, iii) 269 strengthen to $-0.32 \mathrm{~W} \cdot \mathrm{m}^{-2}(+55 \%)$ if the eruption had occurred in pre-industrial times when 270 the background concentrations of aerosols was reduced ${ }^{18}$ indicating that climatic impact of 271 fissure eruptions such as $\mathrm{Laki}^{41}$ in 1783-1784 would not have been as large if it had occurred 272 in the present day.

273 Many studies ${ }^{9,11,42,43}$ suggest that cloud adjustments may be dependent upon meteorological 274 regime, so we ask whether the cloud LWP invariance observed near Holuhraun is simply a 275 special case. We have reproduced the cloud regimes analysis derived from satellite 276 measurements presented in a recent study ${ }^{44}$. We find that, when examining the 2014-15 277 eruption at Holuhraun, we are far from examining a meteorological 'special case', in fact rather the opposite (Supplementary S13); we are examining a region that contains the whole spectrum of liquid-dominated cloud regimes and deducing that, overall, the impact on $L W P$ is minimal.

281 To further support our conclusion, we report results from a different event (Mount Kilauea, 282 Hawaii, Supplementary S14), which degassing rate significantly increased during JuneAugust 2008. The outflow of the plume affected the surrounding trade maritime cumuli $^{24,45,46}$, increasing the SW reflectance; the causal interpretations of this in the literature have varied ${ }^{24,46}$. affecting the surrounding trade maritime cumuli ${ }^{24,45,46}$ and increased the SW reflectance in the outflow of the plume, although with different causal interpretations ${ }^{24,46}$.

287 Again, LWP does not vary, either in the AMSR-E data ${ }^{46}$ or in the MODIS monthly retrievals 288 (Supplementary S14) which again suggests $L W P$ insensitivity in the trade cumulus regime as well. Thus, for a very different meteorological environment dominated by very different cloud regimes, similar conclusions emerge.

292 4. Discussion and Conclusion (507 words of referenced text): 
293 The 2014-15 eruption at Holuhraun presents a unique opportunity to investigate continental-

294 scale aerosol-cloud climatic effects. Using synergistic observations and models driven by an

295 empirical estimate of $\mathrm{SO}_{2}$ emissions ${ }^{33}$ we simulate spatial distributions of $\mathrm{SO}_{2}$ that compare

296 favourably with satellite observations. The HadGEM3 model is able to predict an impact

297 from aerosol-cloud interactions of similar magnitude to the signal found in the MODIS data.

298 Our analysis further highlights that cloud properties are largely unaffected by the eruption

299 beyond the impact on $r_{\text {eff. }}$

300 We repeated the experiment with two additional GCMs and show that HadGEM3 using 301 UKCA, CAM5-NCAR and CAM5-Oslo are able to capture the magnitude of the observed 302 impacts on $r_{\text {eff }}$ despite the lack of explicit representation of processes such as sub-cloud 303 updraft velocities and entrainment, enhancing our confidence in GCMs' ability in predicting 304 the aerosol first indirect effect. However, in line with recent work ${ }^{16}$, modelled responses in the $L W P$ differ significantly. The fact that cloud adjustments via $L W P$ are not identified in the observations of the 2014-15 eruption at Holuhraun indicates that clouds are buffered against $L W P$ changes $^{9-10,12}$, providing evidence that models with a low $L W P$ response display a more convincing behaviour. These findings have wide scientific relevance in the field of climate modelling as, in terms of climate forcing, they suggest that aerosol second indirect effects appear small and climate models with a significant $L W P$ feedback need reassessment ${ }^{15-16,47}$.

311 Despite such massive emissions and large anomalies in $r_{\text {eff, }}$ we estimate a moderate global312 mean radiative forcing of $-0.21 \pm 0.08 \mathrm{~W} \cdot \mathrm{m}^{-2}$ (1 standard deviation, Supplementary S15) for

313 September-October which equates to a global annual mean effective radiative forcing of $314-0.035 \pm 0.013 \mathrm{~W} \cdot \mathrm{m}^{-2}(1$ standard deviation) assuming that a forcing only occurs in 315 September and October 2014. Global emissions of anthropogenic $\mathrm{SO}_{2}$ currently total around $316100 \mathrm{TgSO}_{2} /$ year and the Intergovernmental Panel on Climate Change ${ }^{17,47}$ suggests a best 317 estimate for the aerosol forcing of $-0.9 \mathrm{~W} \cdot \mathrm{m}^{-2}$, yielding a forcing efficiency of -0.009 318 W.m ${ }^{-2} / \mathrm{TgSO}_{2}$. The emissions for September and October 2014 total approximately $4 \mathrm{TgSO}_{2}$, thus the global annual mean radiative forcing efficiency for the 2014-15 eruption at 
320 Holuhraun yields a forcing efficiency of $-0.0088 \pm 0.0024 \mathrm{~W} \cdot \mathrm{m}^{-2} / \mathrm{TgSO}_{2}$ (1 standard

321 deviation). The similarity is remarkable, but may be by chance given the modelled sensitivity

322 to emission location and time (Supplementary S12).

323 Our study is not without caveats given that the observations themselves are uncertain owing 324 to the limitations of satellite retrievals. The modelling is not completely constrained owing to 325 the lack of detailed in-situ observations of e.g. the background aerosol concentrations and 326 plume height. We cannot rule out that models showing small $L W P$ sensitivity to aerosol 327 emission behave as they do because they lack the resolution to represent fine-scale dynamical 328 feedbacks ${ }^{9,12}$. Further high-resolution modelling of the 2014-15 Holuhraun eruption is 329 necessary to evaluate more thoroughly how processes such as autoconversion or droplet 330 evaporation plays a role in buffering the aerosol effect ${ }^{9,12,48,49}$. Bringing many of the different 331 global models together and inter-comparing results of Holuhraun simulations is merited to 332 provide a traceable route for reducing the uncertainty in future climate projections.

334 References:

$335{ }^{1}$ Twomey, S., The influence of pollution on the shortwave albedo of clouds. J. Atmos. Sci., 34:11493361152 (1977).

$337{ }^{2}$ Albrecht, B. A., Aerosols, cloud microphysics, and fractional cloudiness. Science, 245(4923):1227$3381230(1989)$.

$339{ }^{3}$ Haywood, J.M., and Boucher, O., Estimates of the direct and indirect radiative forcing due to 340 tropospheric aerosols: a review. Reviews of Geophysics, 38, 513-543 (2000).

$341{ }^{4}$ Lohmann, U., Koren, I. and Kaufman, Y. J., Disentangling the role of microphysical and dynamical 342 effects in determining cloud properties over the Atlantic. Geophys. Res. Lett., 33, L09802, 343 doi:10.1029/2005GL024625 (2006).

$344{ }^{5}$ Mauger, G. S., and J. R. Norris, Meteorological bias in satellite estimates of aerosol-cloud 345 relationships. Geophys. Res. Lett., 34, L16824, doi:10.1029/2007GL029952 (2007).

$346{ }^{6}$ Gryspeerdt, E., Quaas, J. and Bellouin, N., Constraining the aerosol influence on cloud fraction. J.

347 Geophys. Res. Atmos., 121, 3566-3583, doi:10.1002/2015JD023744 (2016). 
${ }^{7}$ Ackerman, A. S. et al., The impact of humidity above stratiform clouds on indirect climate forcing. Nature, 432, 1014-1017 (2004).

$350 \quad{ }^{8}$ Sandu, I., J. L. Brenguier, O. Geoffroy, O. Thouron, and V. Masson, Aerosol impacts on the diurnal cycle of marine stratocumulus. J. Atmos. Sci., 65, 2705-2718, doi:10.1175/2008JAS2451.1 (2008). ${ }^{9}$ Stevens, B. and Feingold, G., Untangling aerosol effects on clouds and precipitation in a buffered system. Nature, 461, 607-613 (2009).

${ }^{10}$ Seifert, A., Köhler, C., and Beheng, K. D., Aerosol-cloud-precipitation effects over Germany as simulated by a convective-scale numerical weather prediction model. Atmos. Chem. Phys., 12, 709725, doi:10.5194/acp-12-709-2012 (2012).

${ }^{11}$ Lebo, Z. J. and Feingold, G., On the relationship between responses in cloud water and precipitation to changes in aerosol. Atmos. Chem. Phys., 14:11817-11831 (2014).

${ }^{12}$ Seifert, A., T. Heus, R. Pincus, and B. Stevens, Large-eddy simulation of the transient and nearequilibrium behaviour of precipitating shallow convection. J. Adv. Model. Earth Syst., 7, 1918-1937, doi:10.1002/2015MS000489 (2015).

${ }^{13}$ Quaas, J. et al., Aerosol indirect effects - general circulation model intercomparison and evaluation with satellite data. Atmos. Chem. Phys., 9, 8697-8717, doi:10.5194/acp-9-8697-2009 (2009). aerosols. Proc. Natl Acad. Sci., USA 108, 13404-13408, doi:10.1073/pnas.1018526108 (2011).

${ }^{15}$ Stevens, B., Rethinking the Lower Bound on Aerosol Radiative Forcing. J. Clim., 28, 4794-4819, doi:10.1175/JCLI-D-14-00656.1 (2015).

${ }^{16}$ Ghan, S. et al., Challenges in constraining anthropogenic aerosol effects on cloud radiative forcing using present-day spatiotemporal variability. Proc. Natl. Acad. Sci. USA, 113,5804-5811, doi $10.1073 /$ pnas.1514036113(2016).

${ }^{17}$ Boucher, O. et al., Clouds and Aerosols. In: Climate Change 2013: The Physical Science Basis.

Contribution of Working Group I to the Fifth Assessment Report of the Intergovernmental Panel on

373 Climate Change [Stocker, T.F., D. Qin, G.-K. Plattner, M. Tignor, S.K. Allen, J. Boschung, A.

374 Nauels, Y. Xia, V. Bex and P.M. Midgley (eds.)]. Cambridge University Press, Cambridge, United 375 Kingdom and New York, NY, USA (2013).

$376{ }^{18}$ Carslaw, K. S. et al., Large contribution of natural aerosols to uncertainty in indirect Forcing. 
$378{ }^{19}$ Hamilton, D. S. et al., Occurrence of pristine aerosol environments on a polluted planet.

379 Proceedings of the National Academy of Sciences of the United States of America,

380 doi:10.1073/pnas.1415440111 (2014).

$381{ }^{20}$ Lohmann, U. et al., Total aerosol effect: radiative forcing or radiative flux perturbation?. Atmos.

382 Chem. Phys., 10, 3235-3246, doi:10.5194/acp-10-3235-2010 (2010).

$383{ }^{21}$ Gettelman, A., Putting the clouds back in aerosol-cloud interactions. Atmos. Chem. Phys.,

384 15:12397-12411, doi:10.5194/acp-15-12397-2015 (2015).

$385 \quad{ }^{22}$ McCormick, M.P., Thomason, L.W., and Trepte, C.R., Atmospheric effects of the Mt. Pinatubo 386 eruption. Nature, v. 373, p. 399—404, doi:10.1038/373399a0 (1995).

$387{ }^{23}$ Gassó, S., Satellite observations of the impact of weak volcanic activity on marine clouds. $J$.

388 Geophys. Res., 113, D14S19, doi:10.1029/2007JD009106 (2008).

$389{ }^{24}$ Yuan, T., Remer, L. A., and Yu, H., Microphysical, macrophysical and radiative signatures of

390 volcanic aerosols in trade wind cumulus observed by the A-Train. Atmos. Chem. Phys., 11, 7119-

391 7132, doi:10.5194/acp-11-7119-2011 (2011).

$392{ }^{25}$ Schmidt, A. et al., Importance of tropospheric volcanic aerosol for indirect radiative forcing of 393 climate. Atmos. Chem. Phys., 12, 7321-7339, doi:10.5194/acp-12-7321-2012 (2012).

$394{ }^{26}$ Haywood, J. M., Jones, A. and Jones, G. S., The impact of volcanic eruptions in the period 20003952013 on global mean temperature trends evaluated in the HadGEM2-ES climate model. Atmos. Sci. 396 Lett., 15: 92-96. doi:10.1002/as12.471 (2014).

$397{ }^{27}$ Penner, J. E., C. Zhou, and L. Xu, Consistent estimates from satellites and models for the first 398 aerosol indirect forcing. Geophys. Res. Lett., 39, L13810, doi:10.1029/2012GL051870 (2012).

$399{ }^{28}$ Gettelman, A., A. Schmidt, and J.-E. Kristjánsson, Icelandic volcanic emissions and climate. Nature 400 Geoscience, 8, 243, doi:10.1038/ngeo2376 (2015).

$401{ }^{29}$ McCoy, D. T., and D. L. Hartmann, Observations of a substantial cloud-aerosol indirect effect 402 during the 2014-2015 Bárðarbunga-Veiðivötn fissure eruption in Iceland. Geophys. Res. Lett., 42, $403 \quad$ 10,409-10,414, doi:10.1002/2015GL067070 (2015).

$404{ }^{30}$ Clarisse, L. et al., Tracking and quantifying volcanic SO2 with IASI, the September 2007 eruption 405 at Jebel at Tair. Atmos. Chem. Phys., 8, 7723-7734, doi:10.5194/acp-8-7723-2008 (2008).

$406{ }^{31}$ Haywood, J.M. et al., Observations of the eruption of the Sarychev volcano and simulations using 407 the HadGEM2 climate model. J. Geophys. Res., 115, D21212, doi:10.1029/2010JD014447 (2010). 
${ }^{32} \mathrm{Schmidt}$, A. et al., Satellite detection, long-range transport, and air quality impacts of volcanic sulfur

409 dioxide from the 2014-2015 flood lava eruption at Bárðarbunga (Iceland). J. Geophys. Res. Atmos.,

$410 \quad 120$, doi $10.1002 / 2015 J D 023638$ (2015).

$411{ }^{33}$ Thordarson, T., Self, S., Miller, D. J., Larsen, G., \& Vilmundardóttir, E. G., Sulphur release from

412 flood lava eruptions in the Veidivötn, Grímsvötn and Katla volcanic systems, Iceland. Geological

413 Society, London, Special Publications, 213(1), 103-121 (2003).

$414{ }^{34}$ Polashenski, C. M. et al., Neither dust nor black carbon causing apparent albedo decline in

415 Greenland's dry snow zone: Implications for MODIS C5 surface reflectance. Geophys. Res. Lett., 42,

416 doi:10.1002/2015GL065912 (2015).

$417{ }^{35}$ Platnick, S. et al., MODIS Atmosphere L2 Cloud Product (06_L2). NASA MODIS Adaptive

418 Processing System, Goddard Space Flight Center, USA:

419 http://dx.doi.org/10.5067/MODIS/MOD06_L2.006 (2015).

$420 \quad{ }^{36}$ Zhang, Z. and Platnick, S., An assessment of differences between cloud effective particle radius

421 retrievals for marine water clouds from three MODIS spectral bands. Journal of Geophysical

422 Research: Atmospheres (1984-2012), 116(D20) (2011).

$423{ }^{37}$ Stevens, B., and J-L Brenguier, Cloud Controlling Factors - Low Clouds, Heintzenberg, J., and R. J.

424 Charlson, eds. Clouds in the Perturbed Climate System: Their Relationship to Energy Balance,

425 Atmospheric Dynamics, and Precipitation. Strüngmann Forum Report, vol. 2. Cambridge, MA: MIT

426 Press ISBN 978-0-262-01287-4 (2009).

$427{ }^{38}$ Bellouin, N. et al., Aerosol forcing in the CMIP5 simulations by HadGEM2-ES and the role of 428 ammonium nitrate. J. Geophys. Res., doi:10.1029/2011JD016074 (2011).

$429{ }^{39}$ Dhomse, S. S. et al., Aerosol microphysics simulations of the Mt. Pinatubo eruption with the UM-

430 UKCA composition-climate model. Atmos. Chem. Phys., 14, 11221-11246, doi: 10.5194/acp-14-

431 11221-2014 (2014).

$432{ }^{40}$ Kirkevåg, A. et al., Aerosol-climate interactions in the Norwegian Earth System Model - NorESM1-

433 M. Geosci. Model Dev., 6, 207-244, doi:10.5194/gmd-6-207-2013 (2013).

$434{ }^{41}$ Schmidt, A. et al., The impact of the 1783-1784 AD Laki eruption on global aerosol formation

435 processes and cloud condensation nuclei. Atmos. Chem. Phys., 10, 6025-6041, doi:10.5194/acp-10-

$436 \quad 6025-201(2010)$. 
${ }^{42}$ Zhang, S. et al., On the characteristics of aerosol indirect effect based on dynamic regimes in global 438 climate models. Atmos. Chem. Phys., 16, 2765-2783, doi:10.5194/acp-16-2765-2016 (2016).

$439{ }^{43}$ Michibata, T., Suzuki, K., Sato, Y., and Takemura, T., The source of discrepancies in aerosol440 cloud-precipitation interactions between GCM and A-Train retrievals. Atmos. Chem. Phys., 16, 441 15413-15424, doi:10.5194/acp-16-15413-2016 (2016).

$442{ }^{44}$ Oreopoulos, L., N. Cho, D. Lee, and S. Kato, Radiative effects of global MODIS cloud regimes. $J$. 443 Geophys. Res. Atmos., 121, 2299-2317, doi:10.1002/ 2015JD024502 (2016).

$444{ }^{45}$ Eguchi, K. et al., Modulation of cloud droplets and radiation over the North Pacific by Sulfate 445 Aerosol Erupted from Mount Kilauea. SOLA, 7, 77-80, doi:10.2151/sola.2011-020 (2011).

$446{ }^{46}$ Mace, G. G., and A. C. Abernathy, Observational evidence for aerosol invigoration in shallow 447 cumulus downstream of Mount Kilauea. Geophys. Res. Lett., 43, 2981-2988, 448 doi:10.1002/2016GL067830 (2016).

$449{ }^{47}$ Myhre, G. et al., Anthropogenic and Natural Radiative Forcing. In: Climate Change 2013: The 450 Physical Science Basis. Contribution of Working Group I to the Fifth Assessment Report of the 451 Intergovernmental Panel on Climate Change [Stocker, T.F., D. Qin, G.-K. Plattner, M. Tignor, S.K. 452 Allen, J. Boschung, A. Nauels, Y. Xia, V. Bex and P.M. Midgley (eds.)]. Cambridge University Press, 453 Cambridge, United Kingdom and New York, NY, USA (2013).

$454{ }^{48}$ Golaz, J.-C., L. W. Horowitz, and H. Levy, Cloud tuning in a coupled climate model: impact on 455 20th century warming. Geophys. Res. Lett., 40, 2246-2251, doi:10.1002/grl.50232 (2013).

$456{ }^{49}$ Zhou, C. and Penner, J. E.: Why do general circulation models overestimate the aerosol cloud 457 lifetime effect? A case study comparing CAM5 and a CRM. Atmos. Chem. Phys., 17, 21-29, 458 doi:10.5194/acp-17-21-2017 (2017).

459

460 List of Supplementary Materials:

461 SUPPLEMENTARY_INFORMATION.docx

462 SI-Cloud-Animation.mp4

463 SI-SO2_animation.mp4 
465 Acknowledgements: JMH, AJ, MD, BTJ, CEJ, JRK and FMOC were supported by the Joint UK 466 BEIS/Defra Met Office Hadley Centre Climate Programme (GA01101). The National Center for

467 Atmospheric Research is sponsored by the U.S. National Science Foundation. SB and LC are 468 respectively Research Fellow and Research Associate funded by F.R.S.-FNRS. PS acknowledges 469 support from the European Research Council (ERC) project ACCLAIM (Grant Agreement FP7470 280025). JMH, FFM, DGP and PS were part funded by the UK Natural Environment Research 471 Council project ACID-PRUF (NE/I020148/1). AS was funded by an Academic Research Fellowship 472 from the University of Leeds and a NERC urgency grant NE/M021130/1 (The source and longevity 473 of sulphur in an Icelandic flood basalt eruption plume). RA was supported by the NERC SMURPHS 474 project NE/N006054/1. GWM was funded by the National Centre for Atmospheric Science, one of 475 the UK Natural Environment Research Council's research centres. DPG is funded by the School of 476 Earth and Environment at the University of Leeds. GWM and SD acknowledge additional EU funding 477 from the ERC under the FP7 consortium project MACC-II (grant agreement 283576) and Horizon 2020 project MACC-III (grant agreement 633080). GWM, KSC and DG were also supported through the financial support via the Leeds-Met Office Academic Partnership (ASCI project). The work done with CAM5-Oslo is supported by the Research Council of Norway through the EVA project (grant 229771), NOTUR project nn2345k and NorStore project ns2345k. The following researchers have contributed substantially to the development version of CAM5-Oslo used in this study: Kari Alterskjær, Alf Grini, Matthias Hummel, Trond Iversen, Alf Kirkevåg, Dirk Olivié, Michael Schulz, Øyvind Seland. The AQUA/MODIS MYD08 L3 Global 1 Deg. dataset was acquired from the Level-1 and Atmosphere Archive \& Distribution System (LAADS) Distributed Active Archive Center (DAAC), located in the Goddard Space Flight Center in Greenbelt, Maryland https://ladsweb.nascom.nasa.gov/ This work is dedicated to the memory of Jón Egill Kristjánsson who died in a climbing accident in Norway. Jón Egill was a very active, talented and internationally respected researcher, and will be sadly missed.

Author contributions: FFM (Text, processing and analysis of the satellite data and the model results), JMH (Text, analysis of the satellite data and the model results, radiative transfer 
contribution to the text), LC and SB (processing of the IASI data and contribution to the text), LO,

495 NC and DL (MODIS cloud regimes), DPG (estimate of CDNC from MODIS data), TT and MEH 496 (provide emission estimates for the 2014-15 eruption at Holuhraun). AJ, NB, OB, KSC, SD, GWM, 497 AS, HC, MD, AAH, BTJ, CEJ, FMOC, DGP, PS, (contribution to the development of UKCA), GM, 498 SP, GLS, HT, JRK (discussion contributing to text and/or help with the MODIS data).

499

500 Author Information: The authors declare no competing financial interests. Correspondence and 501 material requests should be addressed to Florent Malavelle (f.malavelle@exeter.ac.uk)

\section{Figure legends:}

503 Figure 1. The column loading of sulphur dioxide. First column: processed data from HadGEM3 masked using positive detections of $\mathrm{SO}_{2}$ from IASI and spatially and temporally coherent plume data from HadGEM3. Second column: processed data from IASI re-gridded onto the regular HadGEM3 grid. The column loading are expressed in Dobson Units (DU), with 1 DU equivalents to approximately $0.0285 \mathrm{~g}\left[\mathrm{SO}_{2}\right] \cdot \mathrm{m}^{-2}$. In each case 'avg' represents the average concentration derived within the plume.

509 Figure 2. Changes in cloud properties detected by MODIS AQUA for October 2014. The mean

510 changes in (a) cloud droplet effective radius ( $\mu m$ ) and (c) liquid water path $\left(g . m^{-2}\right)$ with

511 corresponding zonal means. The probability distributions of absolute cloud droplet effective radius

512 (b) and liquid water path (d) for the year 2014 (blue) and the 2002-2013 mean (green). Changes correspond to the deviation from the 2002-2013 mean. Stippling in a) and c) represent areas of 95\% confidence level significant perturbation based on a two-tailed Student's t-test. Grey shading in the zonal means represent the standard deviation over 2002-2013.

516 Figure 3. Changes in cloud properties modelled by HadGEM3 for October 2014. The mean

517 changes in (a) cloud droplet effective radius ( $\mu m)$ and (c) liquid water path $\left(g . m^{-2}\right)$ with

518 corresponding zonal means. The probability distributions of absolute cloud droplet effective radius

519 (b) and liquid water path (d) for 2014 including (blue) or excluding (gold) the Holuhraun emissions, 520 and the 2002-2013 mean (green). Changes correspond to the deviation from the 2002-2013 mean. 
$523 \quad 2002-2013$.

524 Figure 4. Modelled perturbations from HadGEM3 using UKCA during the Sept-Oct 2014 period.

525 Showing perturbations for a) AOD, b) $\left.N_{d}, c\right) \mathrm{r}_{\mathrm{eff}}$, d) LWP, e) $\tau_{\text {cloud, }}$ and f) Top of Atmosphere (ToA) net

$526 S W$ radiation. Zonal means are shown for the $44^{\circ} \mathrm{N}-80^{\circ} \mathrm{N}, 60^{\circ} \mathrm{W}-30^{\circ} \mathrm{E}$ analysis region. The shaded

527 regions represent the natural variability in the simulations from 2002-2013. Values outside of the

528 light grey (respectively dark grey, bottom row) shaded regions represent significant perturbations at

529 the 95\% (respectively 67\%) confidence level based on a two-tailed Student's t-test. Red lines

530 represent $\mathrm{HOL}_{2014}$ minus $\mathrm{NO} \mathrm{HOL}_{2014}$ and blue lines represent $\mathrm{HOL}_{2014}$ minus $N O \mathrm{HOL}_{2002-2013}$.

531 Figure 5. Multi-model estimates of the changes in cloud properties for October 2014. Left column

532 shows $\Delta r_{e f f}(\mu m)$ and right column $\triangle L W P\left(\right.$ g. $\left.m^{-2}\right)$ determined from HadGEM3 using the 2-moment

533 UKCA/GLOMAP-mode aerosol scheme (first row), HadGEM3 using the single moment CLASSIC

534 aerosol scheme (second row) CAM5-NCAR (third row), CAM5-Oslo (fourth row) and AQUA MODIS

535 (last row). Note that MODIS anomalies show the aerosol impacts plus the meteorological variability

536 while the model simulations show the impact of aerosols only (Supplementary S7). 


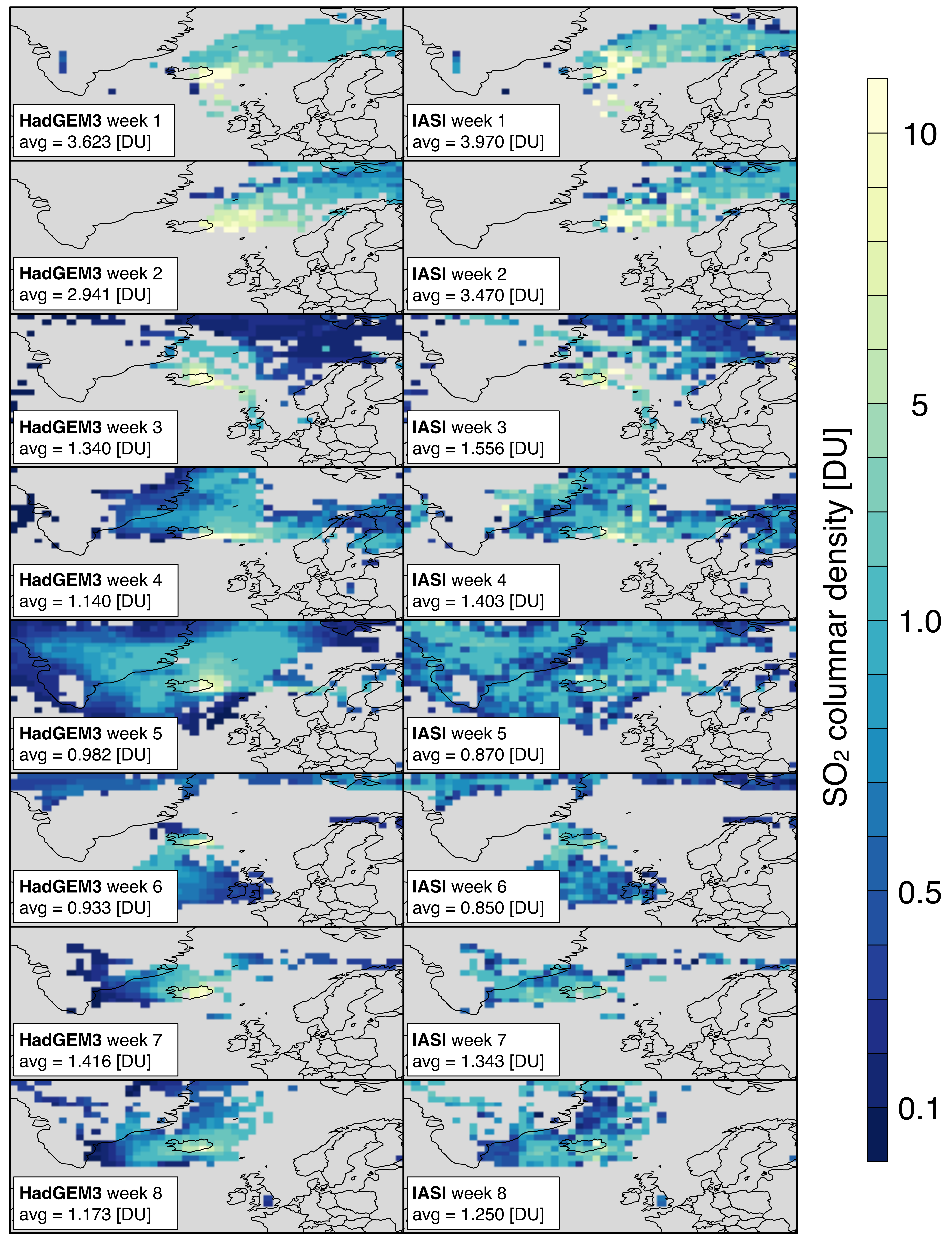




\section{AQUA MODIS - October 2014}

a

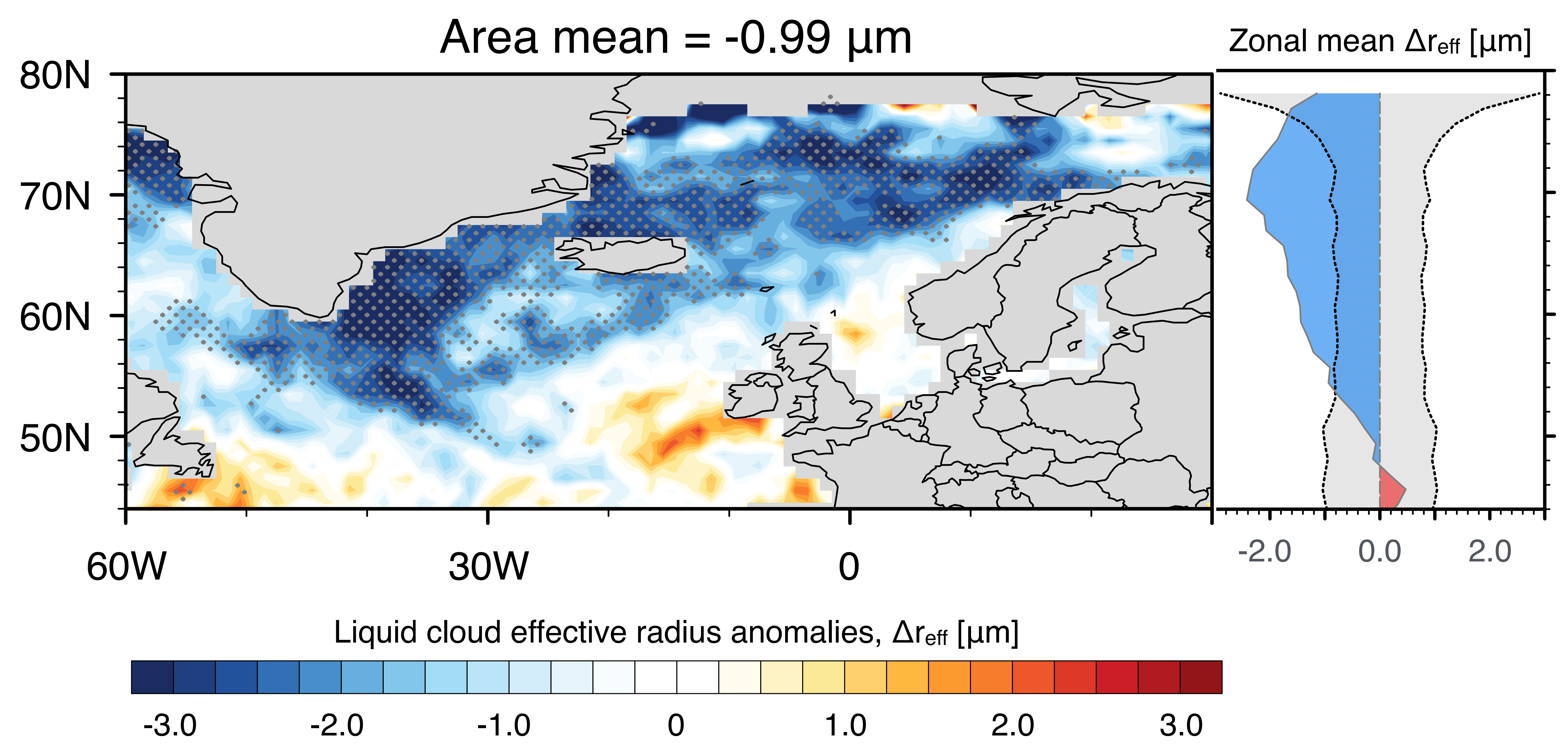

C

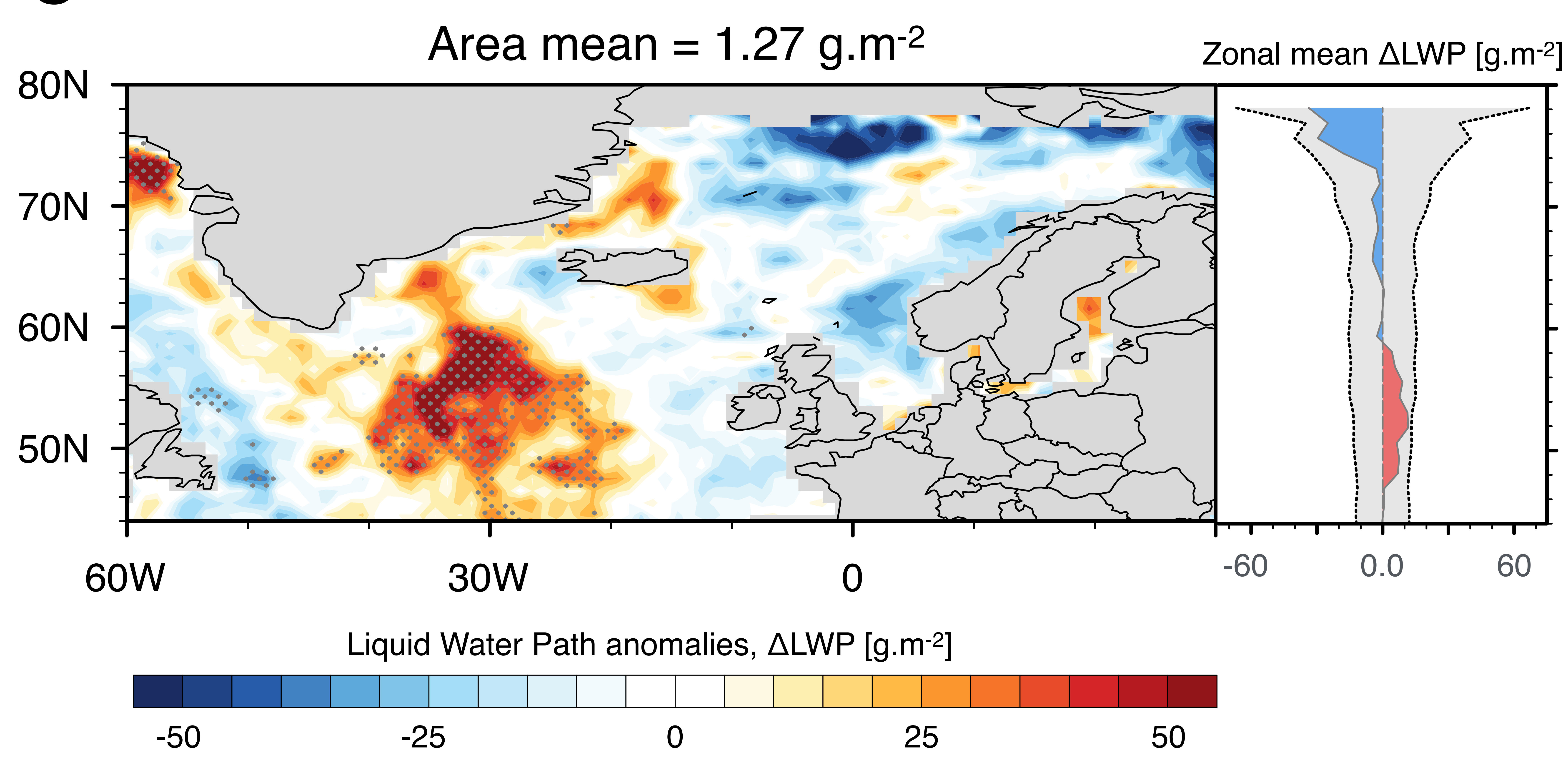

b

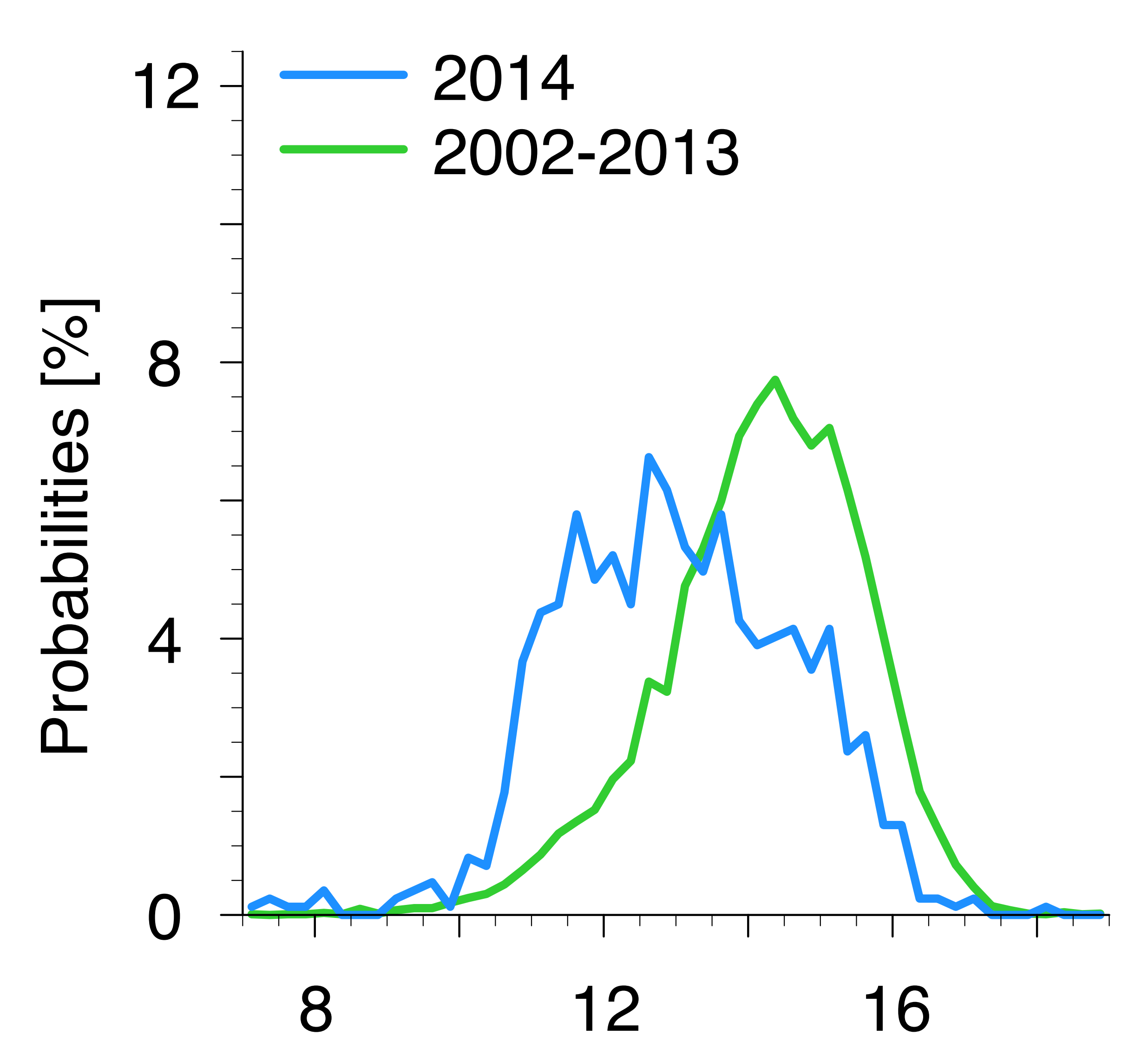

Liquid cloud effective radius [ $\mu \mathrm{m}]$

d

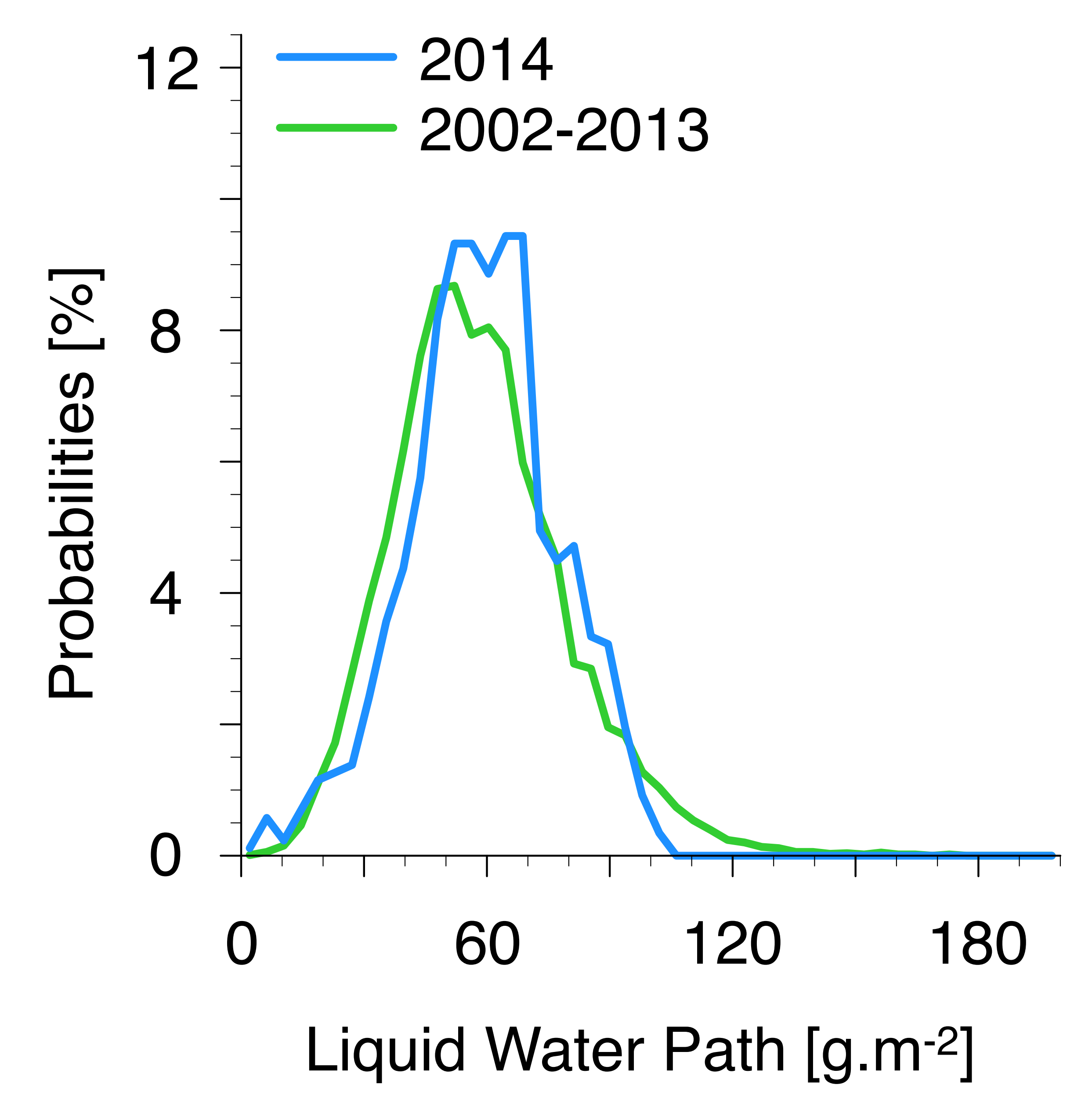




\section{HadGEM3-UKCA - October 2014}

a

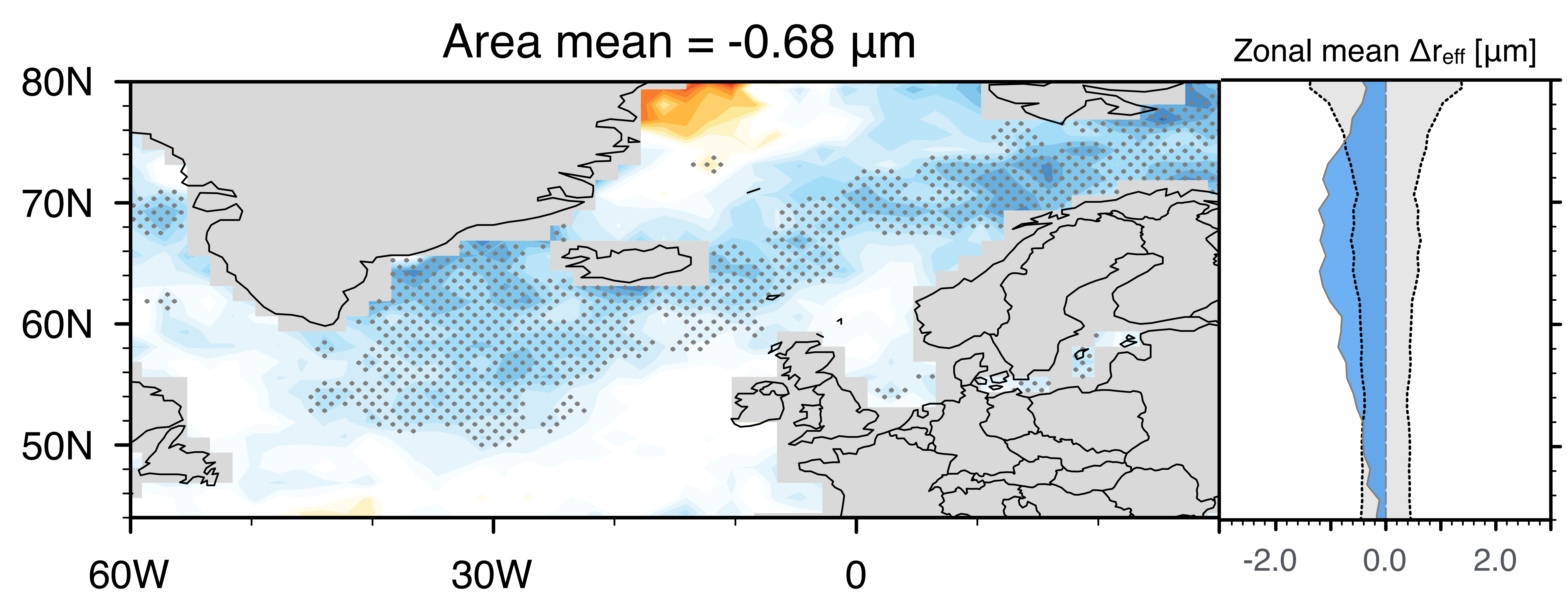

Liquid cloud effective radius anomalies, $\Delta \mathrm{r}_{\text {eff }}[\mu \mathrm{m}]$

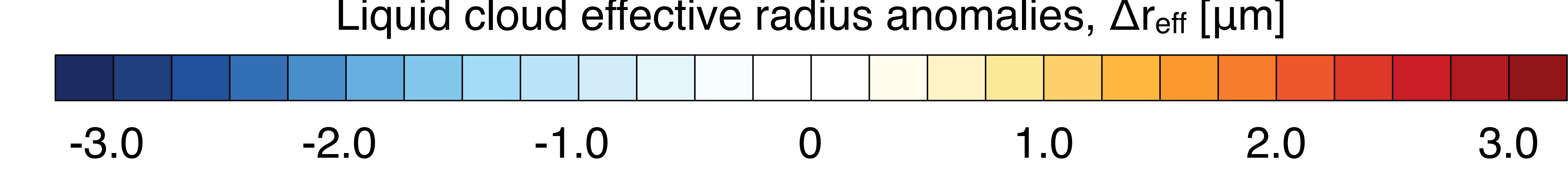

C

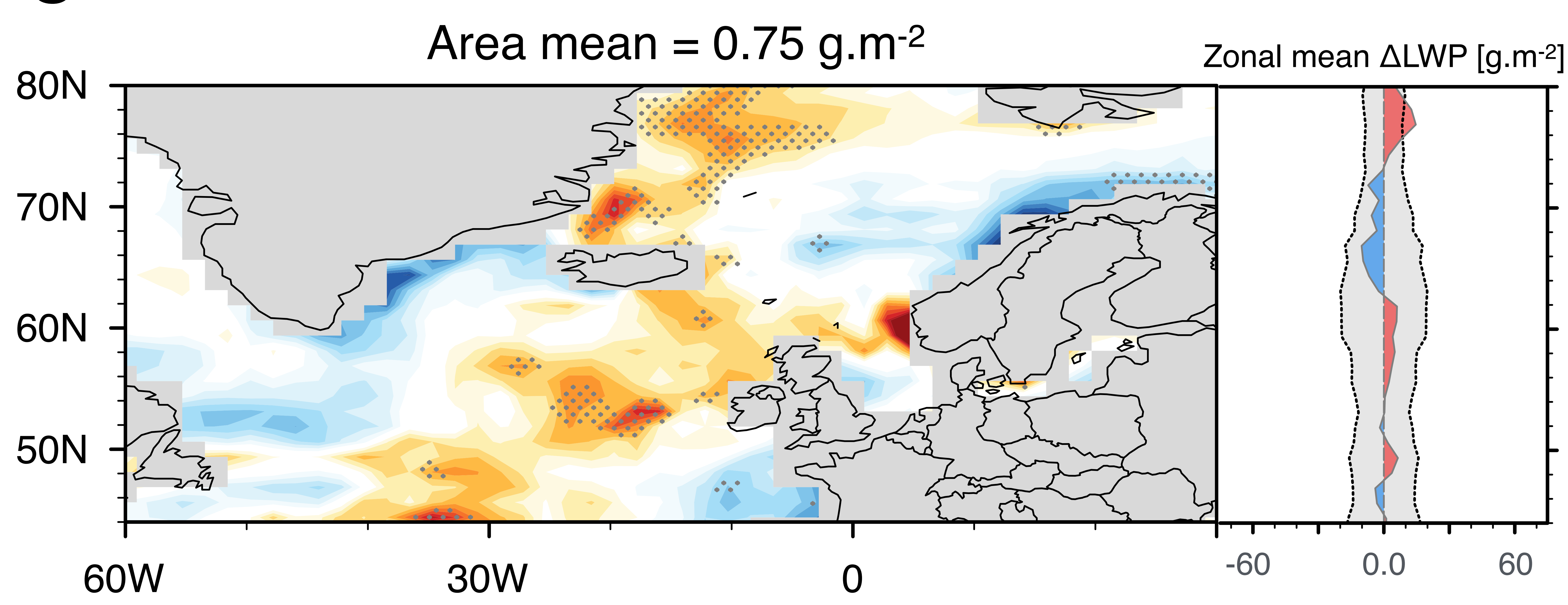

Liquid Water Path anomalies, $\Delta$ LWP [g.m-2] b

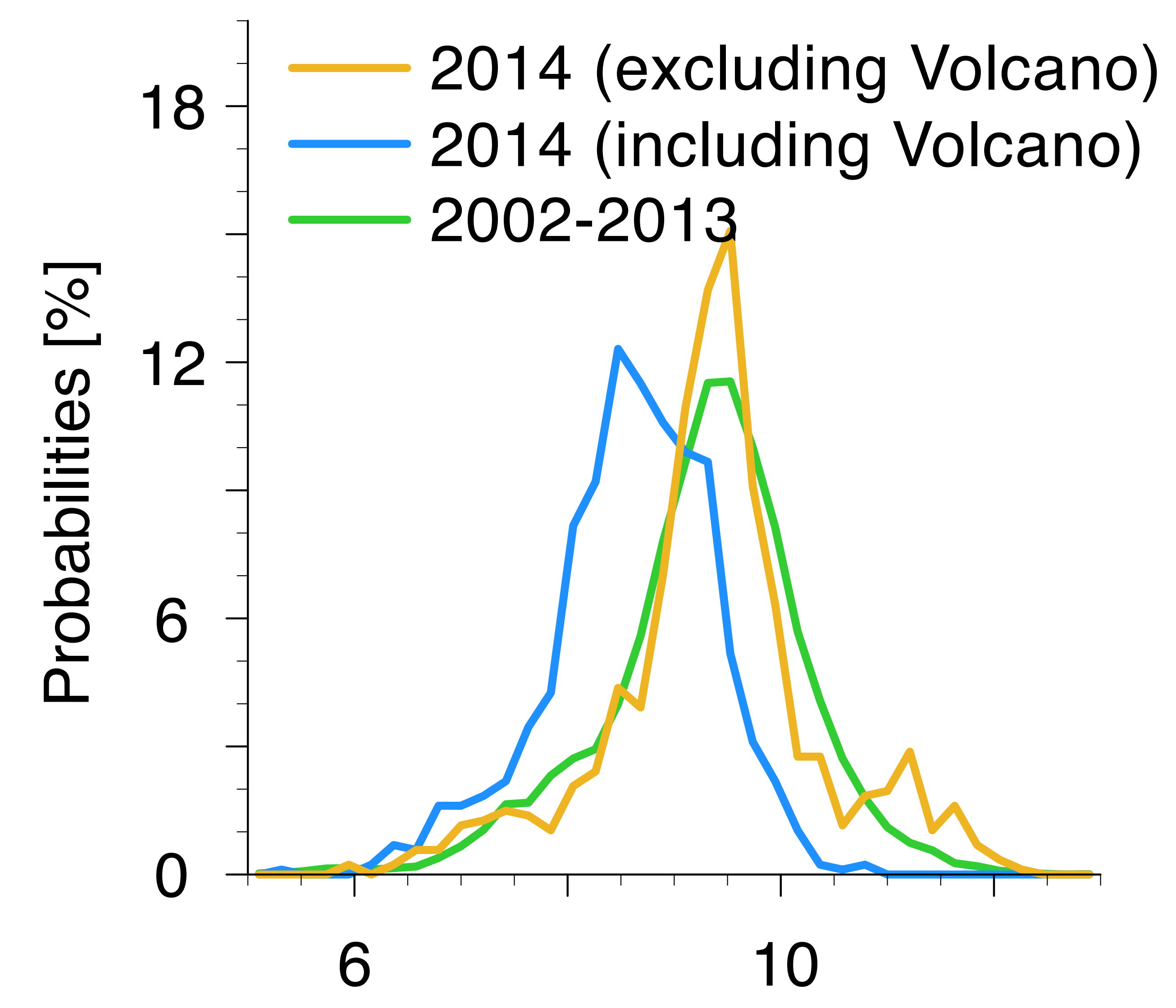

Liquid cloud effective radius [ $\mu \mathrm{m}]$

d

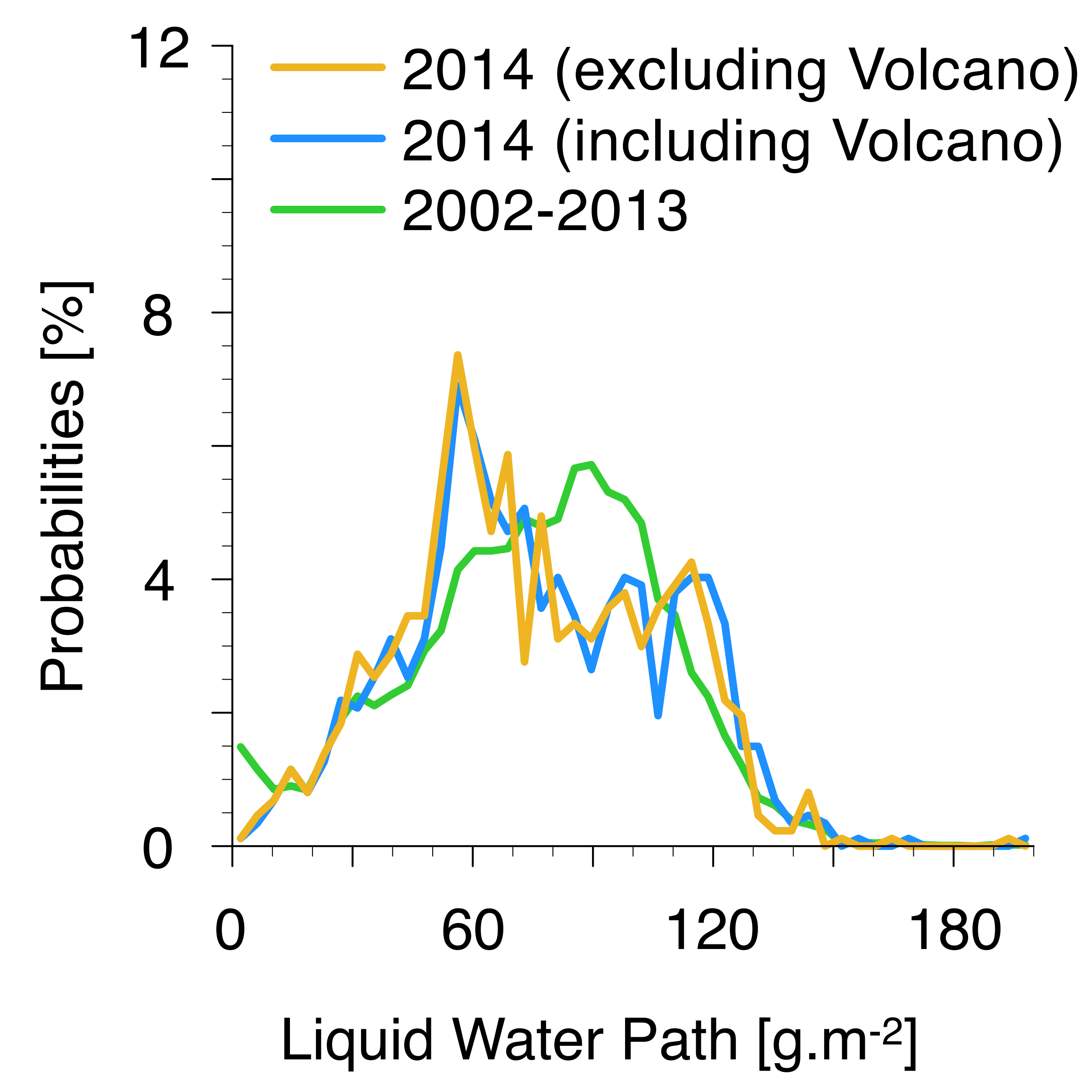


a

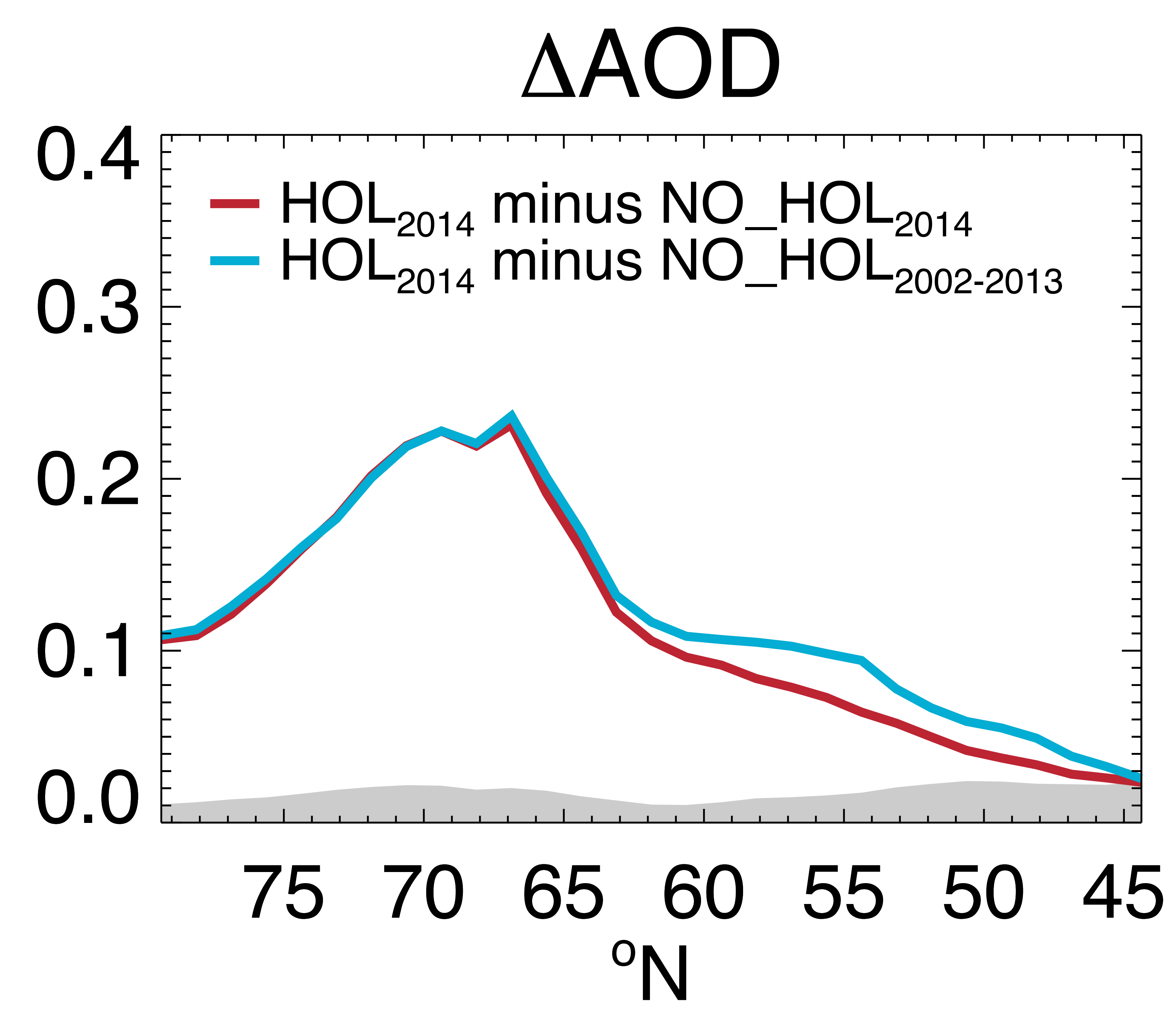

d

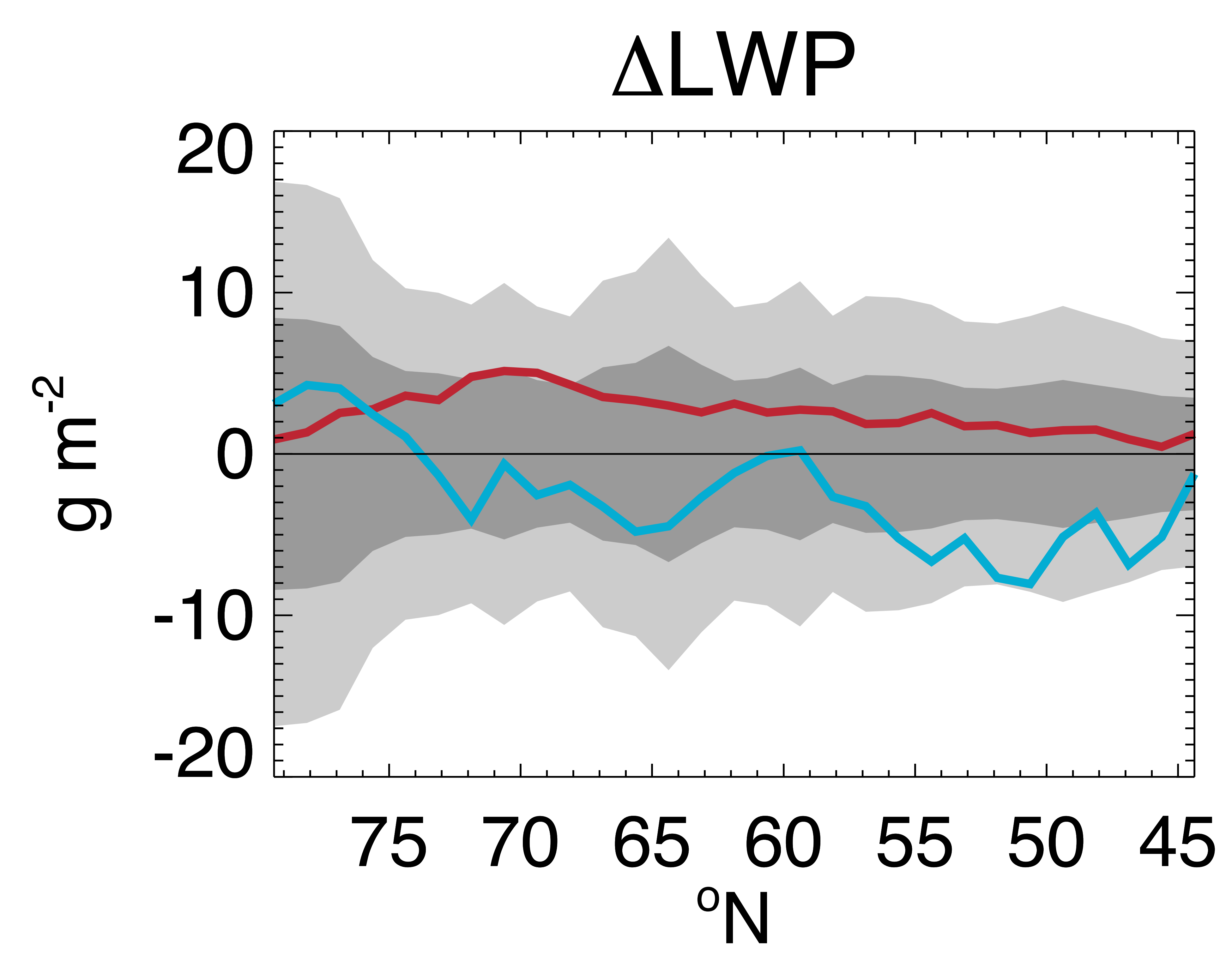

b

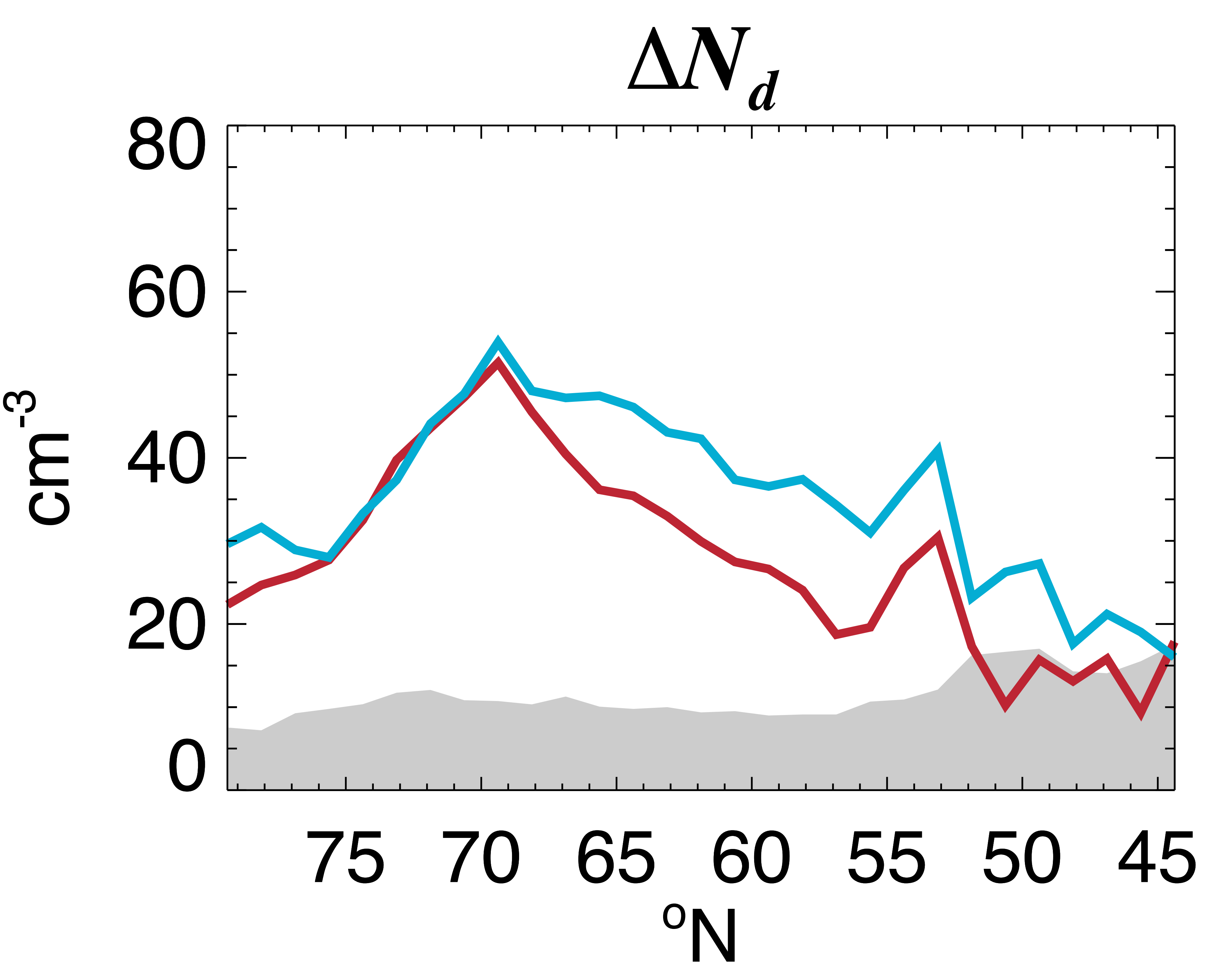

e

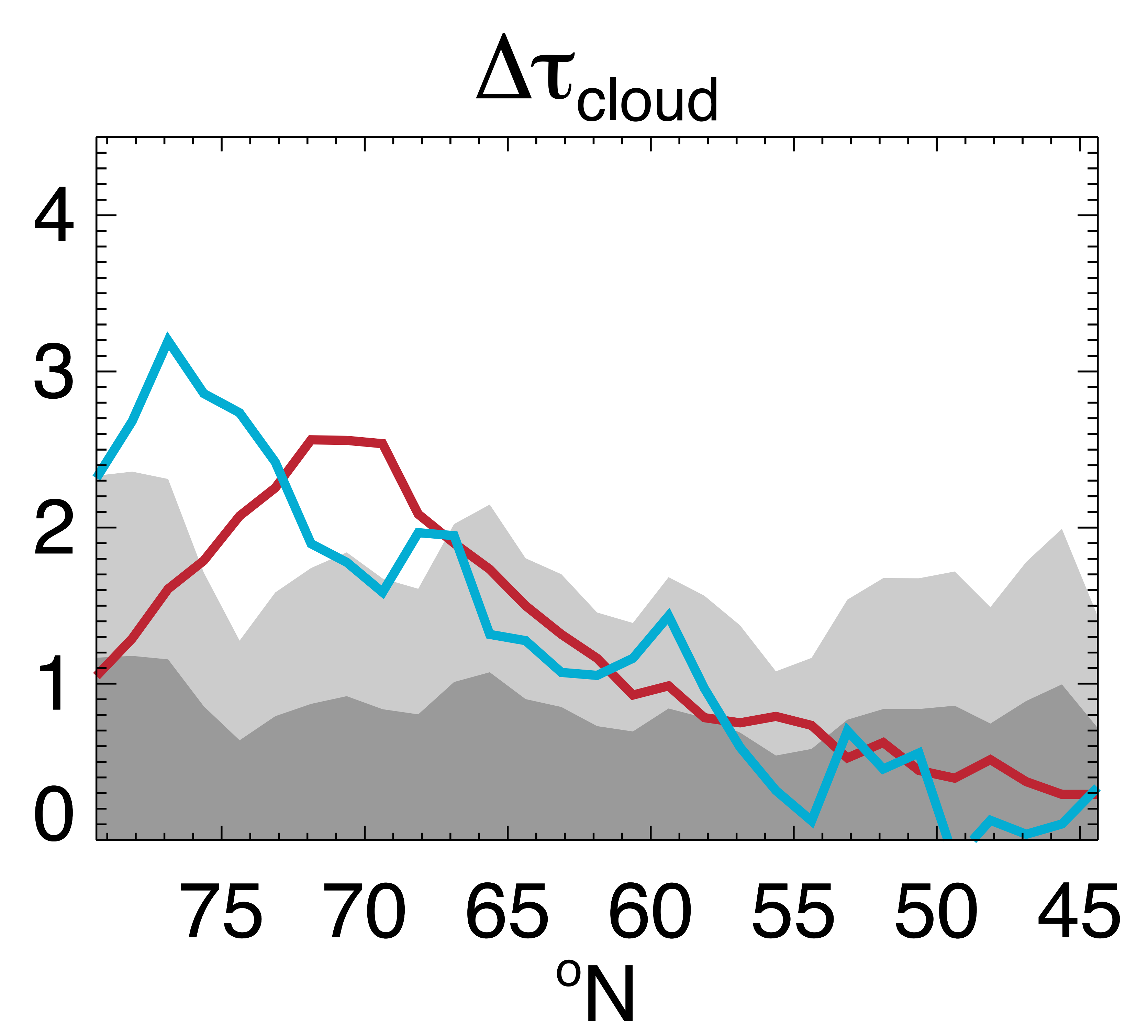

C

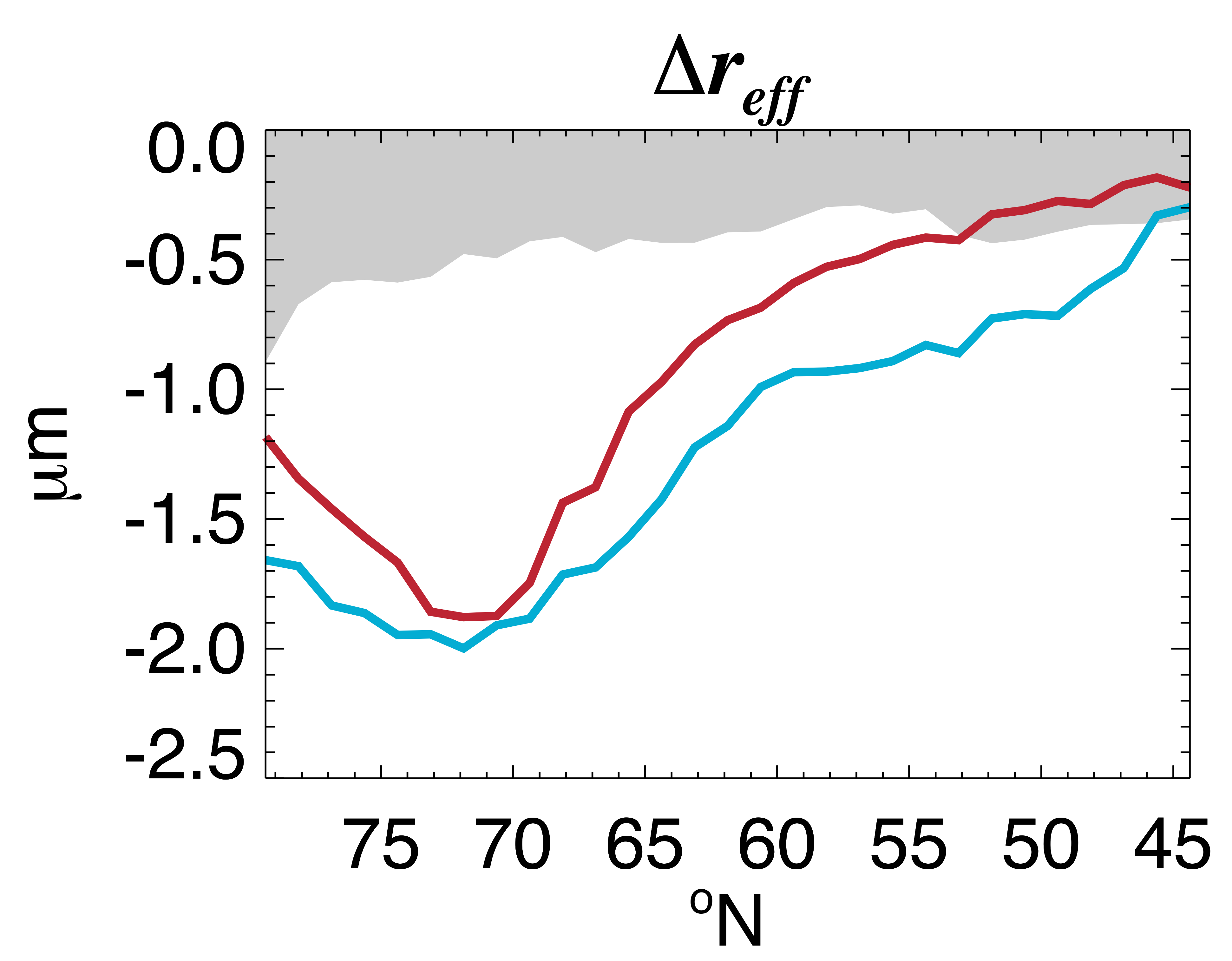

f

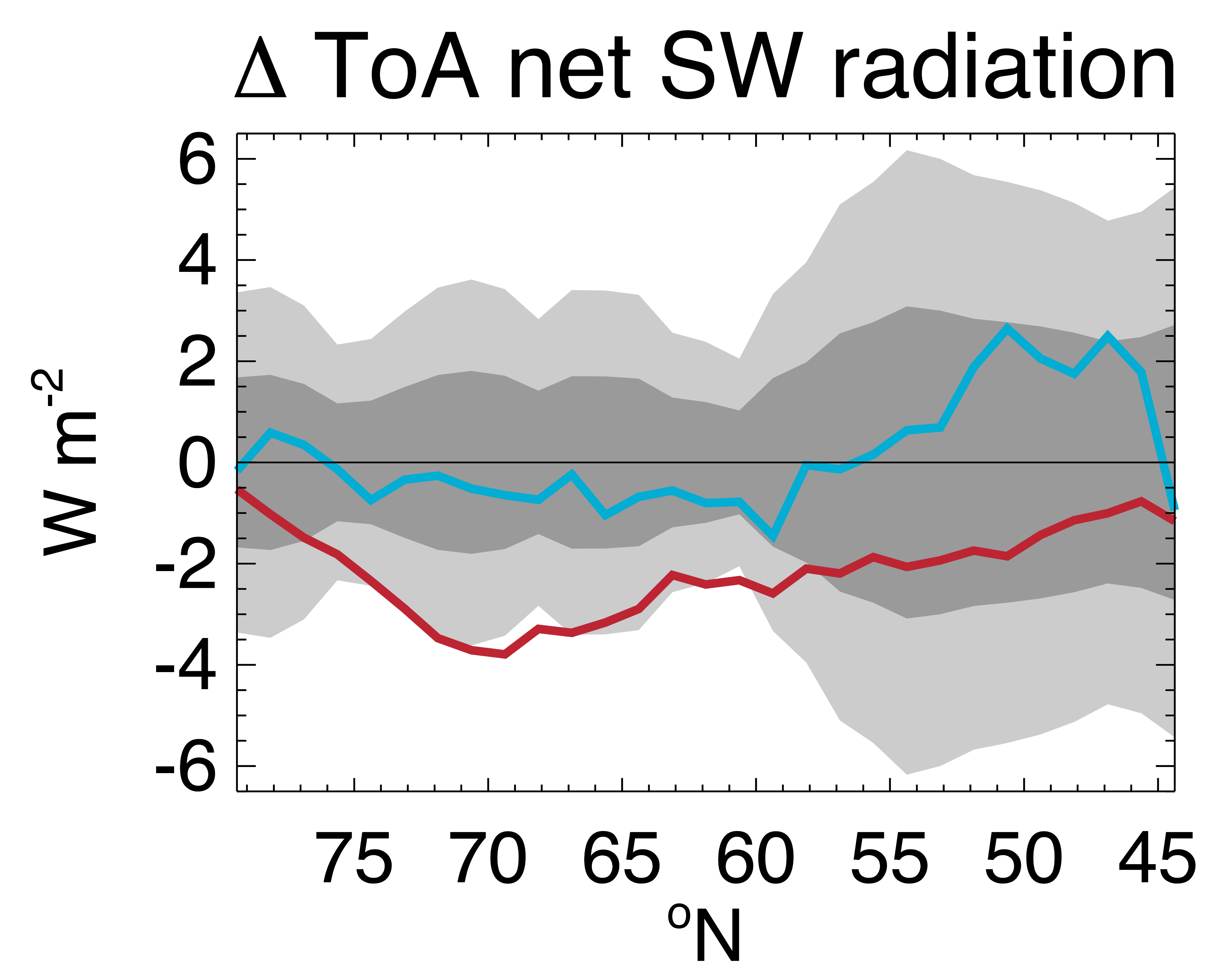


HadGEM3-UKCA

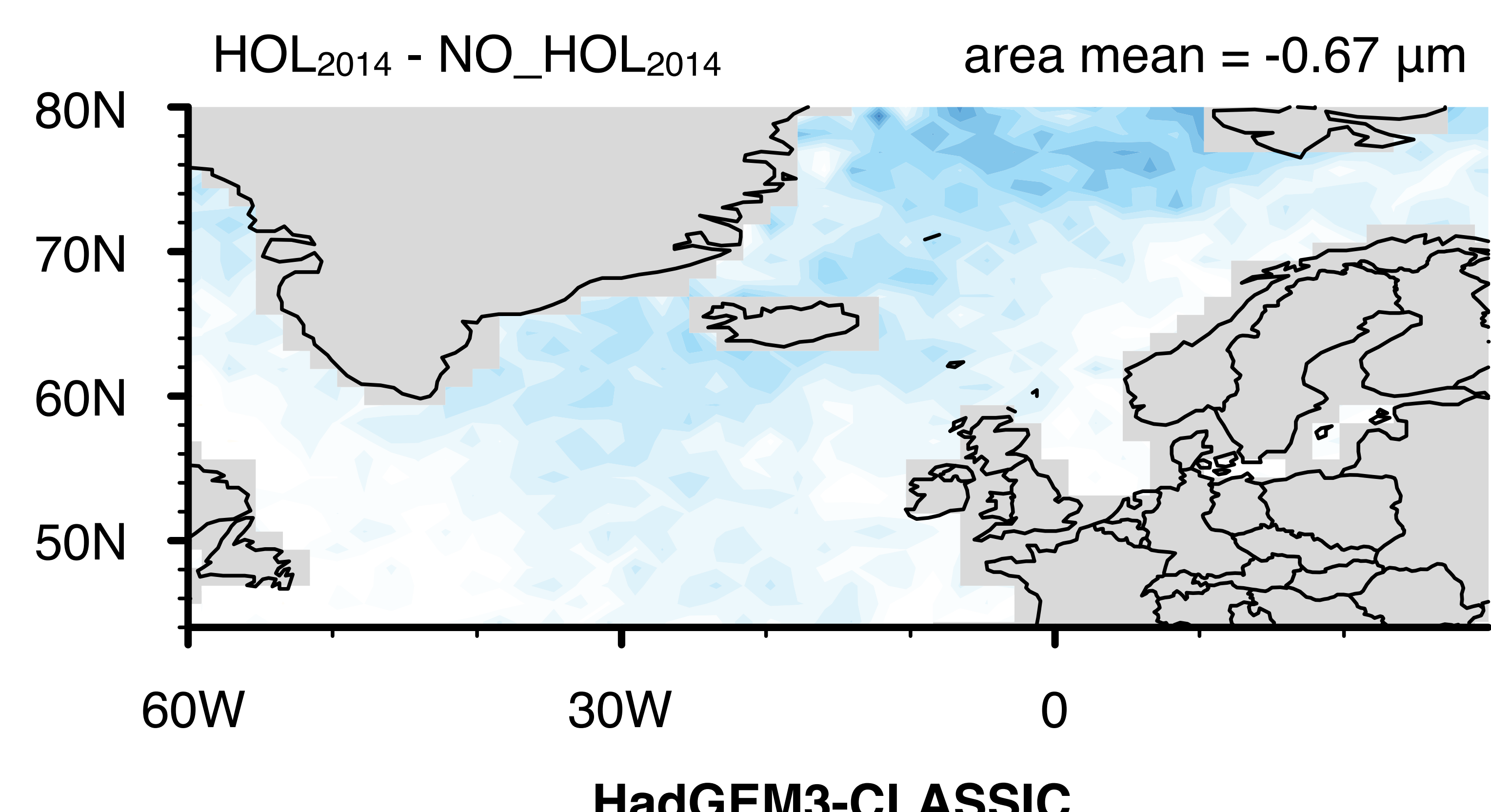

HadGEM3-CLASSIC

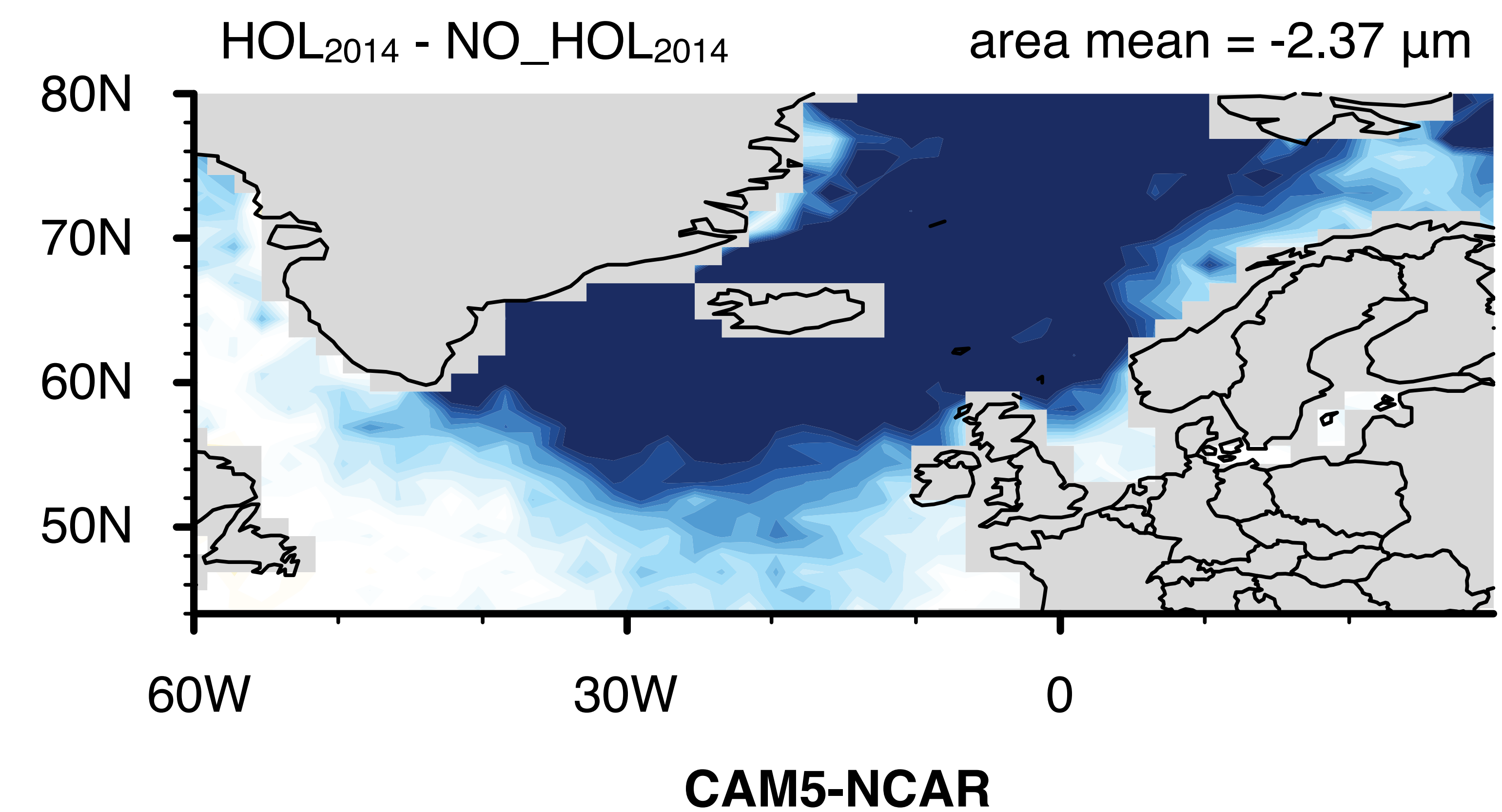

CAM5-NCAR
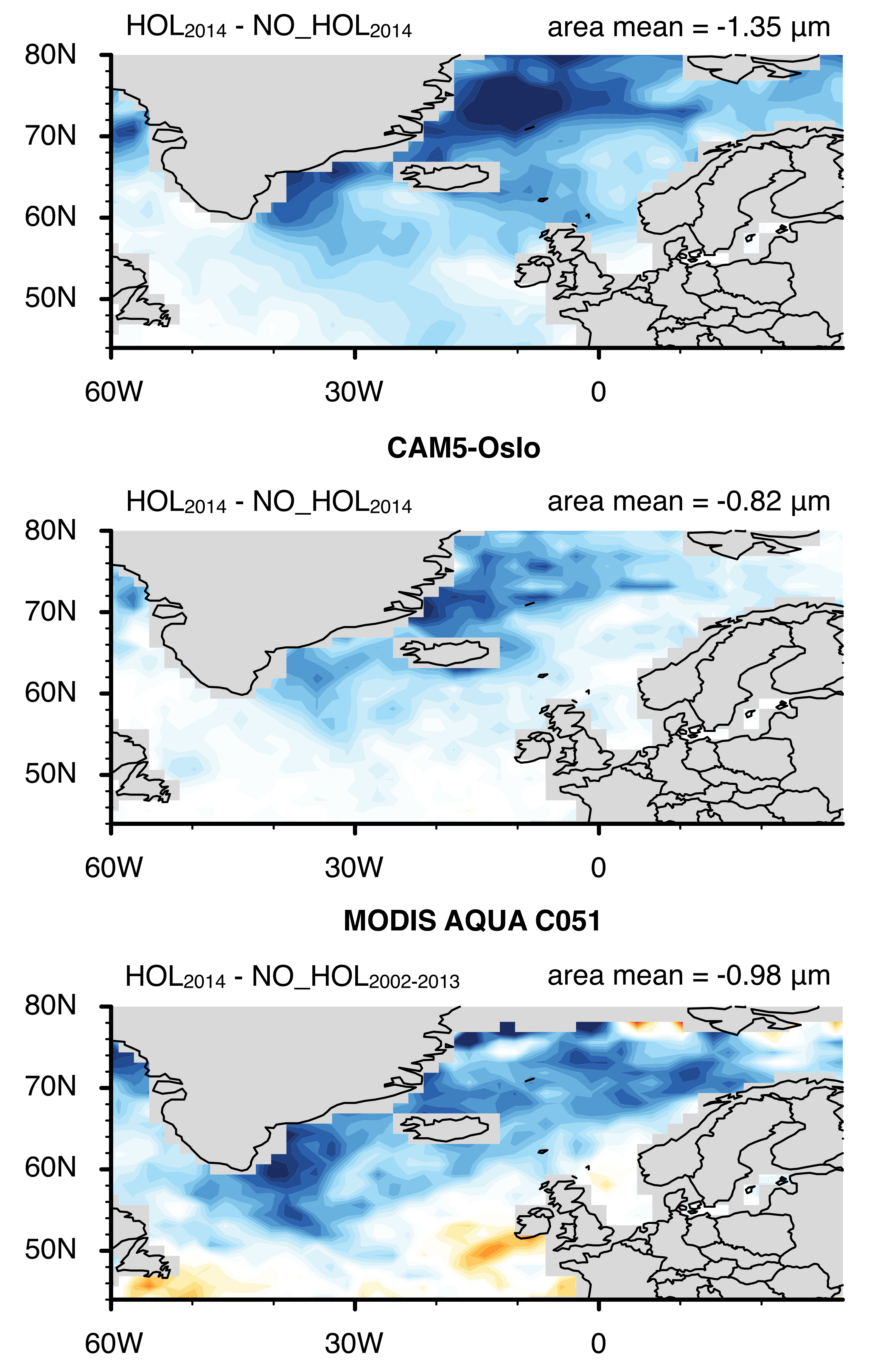

Liquid cloud effective radius anomalies, $\Delta r_{\text {eff }}[\mu \mathrm{m}]$

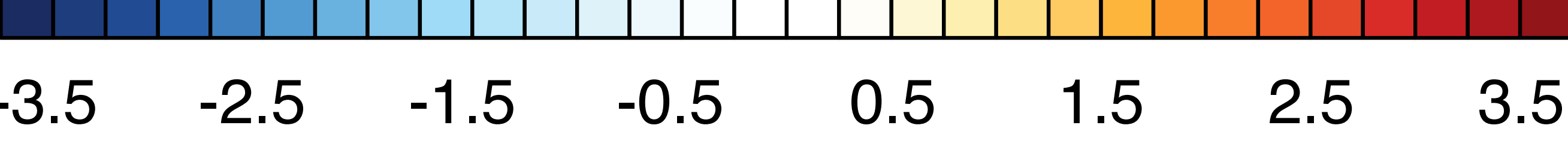
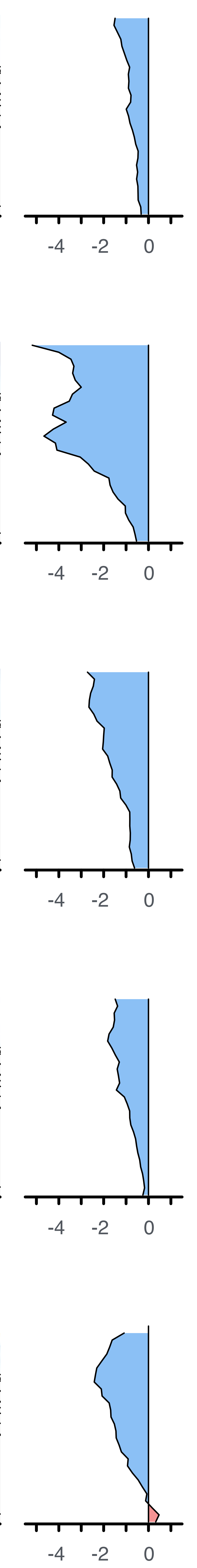

\section{HadGEM3-UKCA}

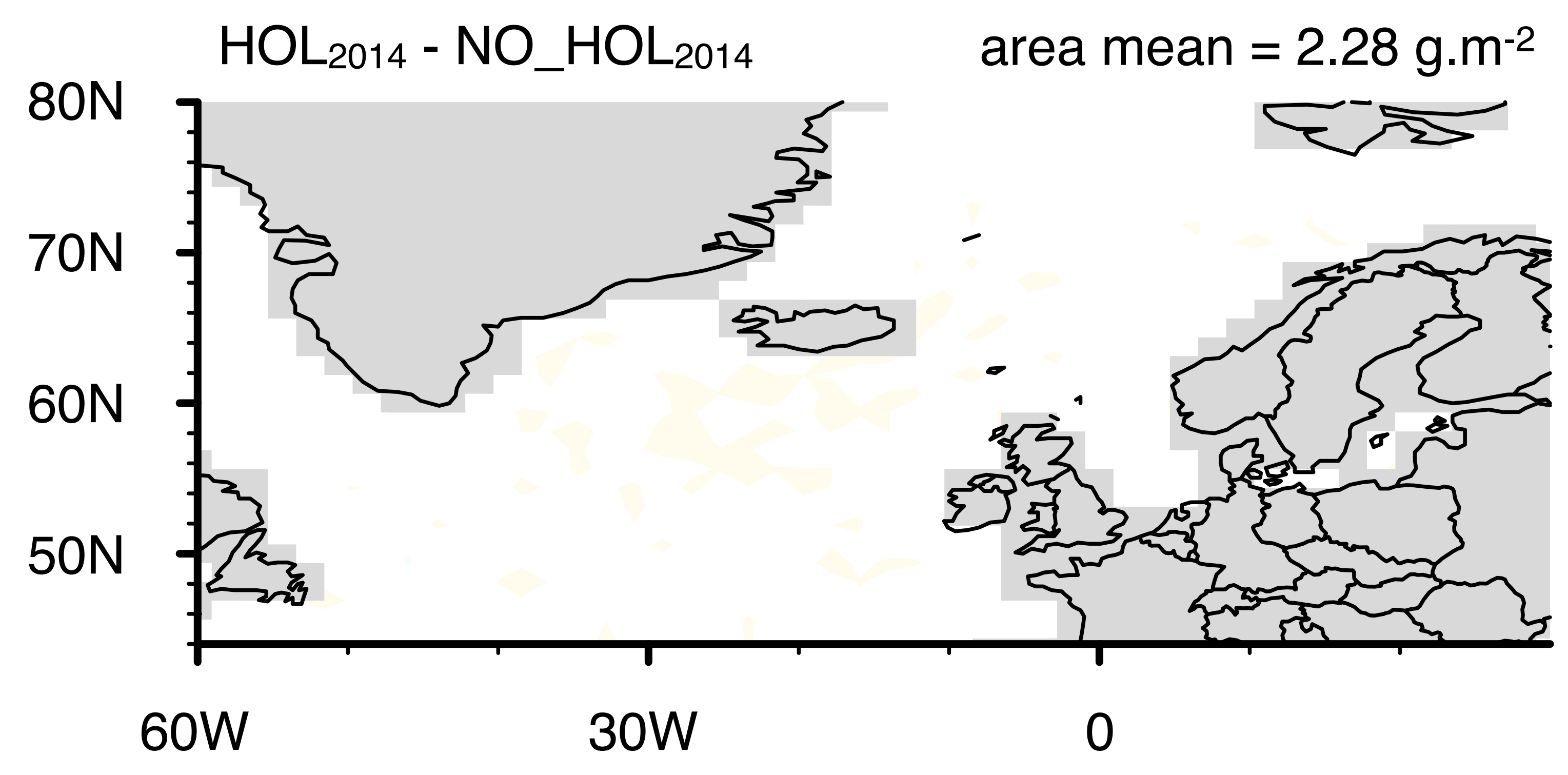

HadGEM3-CLASSIC
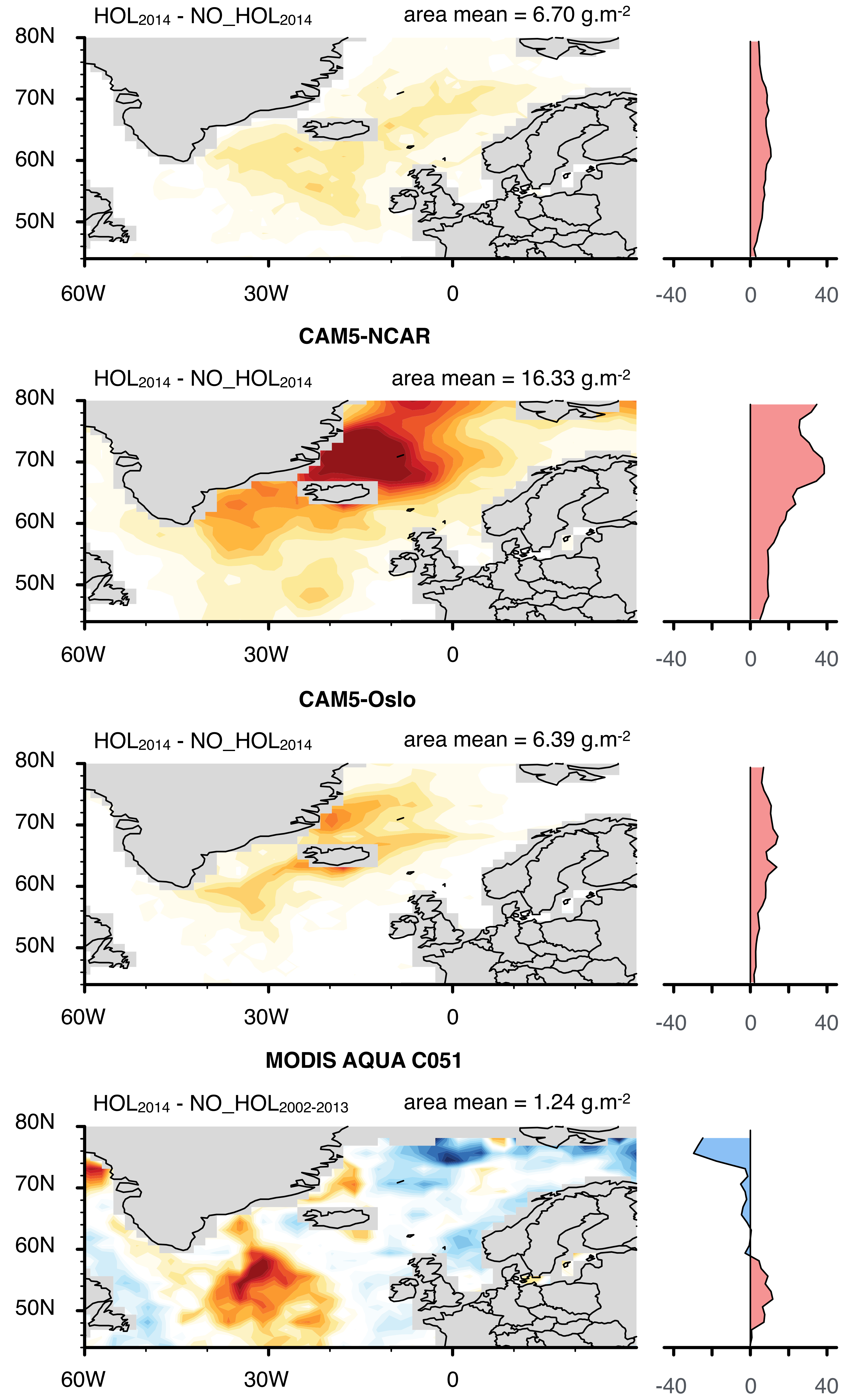

Liquid Water Path anomalies, $\Delta$ LWP [g. $\left.\mathrm{m}^{-2}\right]$

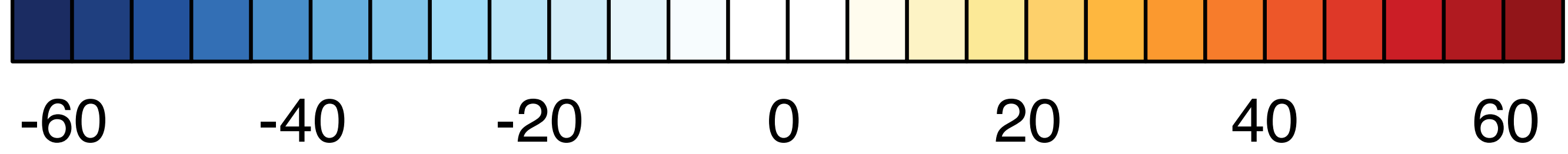

